\title{
A Review on Durability of Alkali-activated System from Sustainable Construction Materials to Engineering Infrastructures
}

\author{
Wengui Li, ${ }^{1 *}$ Zhuo Tang, ${ }^{1}$ Vivian W. Y. Tam, ${ }^{2}$ Xinyu Zhao and Kejin Wang ${ }^{1,4}$
}

With growing concerns for greenhouse gas emissions, alkali-activated materials (AAMs) have received significant attention due to the benefit of low carbon footprint. In the process of promoting large-scale and commercialized applications of AAMs, one of the most significant concerns is the long-term durability. This work presents a critical review on the durability performance of alkali-activated system. At the material level, this work reviews factors influencing the mass transport properties of AAMs, and effects of a number of factors such as chemical activators, raw materials, curing regimes, and exposure environments on the durability of AAMs subjected to both physically and chemically induced deterioration. At the structure level, the durability performance of structures made from AAMs, including beam, slab, box culvert, and repairing materials and protection coating under extreme conditions are reviewed. The review indicates that AAMs have potentials to manufacture durable materials by appropriate selection of raw materials, chemical activators and optimization of mixing design. Furthermore, perspectives are proposed for the further study on the durability of AAMs at both material and structure levels. The related results are of interest to the research community as well as to the stakeholders of AAMs industries who seek sustainability in their products.

Keywords: Alkali-activated materials; Durability; Mass transport; Physically induced deterioration; Chemically induced deterioration; Structure performance

Received 16 December 2018, Accepted 6 February 2019

DOI: $10.30919 / \mathrm{esmm} 5 \mathrm{f} 204$

\section{Introduction}

Ordinary portland cement (OPC), with a total production of 4 billion tons in 2017 , is one of the most common building materials used in construction. ${ }^{1}$ Cement sector is highly intensive in greenhouse gas emissions as producing 1.0 ton of Portland cement clinker generates approximately 1.0 ton of greenhouse gas, involving 0.55 ton from calcination and 0.39 ton in burning fossil fuel. ${ }^{2}$ As a result, the cement plants worldwide emit roughly $5-8 \%$ of the total man-made greenhouse gas emissions. ${ }^{3}$ Apart from massive greenhouse-gas emissions, the cement industry is also facing an enormous challenge from the serious shortage of natural resources as opposed to the increasing demand for cement or concrete products. ${ }^{4}$ Consequently, developing valid alternatives to OPC is an effective option to overcome the obstacles aforementioned. Alkali-activated materials (AAMs), as a new type of inorganic cementitious materials, are resulted from the alkali activation

Center for Built Infrastructure Research, School of Civil \& Environmental Engineering, University of Technology Sydney, Sydney, NSW 2007, Australia

2 School of Computing, Engineering and Mathematics, Western Sydney University, Penrith, NSW 2751, Australia

3 State Key Laboratory of Subtropical Building Science, South China University of Technology, Guangzhou, Guangdong 510640, China

${ }^{4}$ Department of Civil, Construction and Environmental Engineering, Iowa State University, Ames, IA 50011, USA

*E-mail:wengui.li@uts.edu.au of solid aluminosilicate precursors: normally derived from industrial byproducts or solid waste. ${ }^{5}$ AAMs are featured with reasonable workability in the fresh state, excellent mechanical properties in hardened conditions, and a notable reduction in carbon footprint compared to OPC, and therefore have a great potential to replace OPC. ${ }^{6}$

Additionally, AAMs could contribute to the sustainable development goal by recovering resources from waste and minimizing waste disposal by landfill. ${ }^{5}$ It is well known that only a minor part of industrial waste products is recycled, and most are disposed of in landfills, which results in the pollution of water and soil. ${ }^{7}$ AAMs incorporate a much higher proportion of waste material than conventional blended cement and other existing or evolutionary technologies, and would assist the waste producers to reduce required storage and rehabilitation costs or even provide financial benefit from sale. Moreover, due to the pseudo- or proto-zeolitic nature, AAMs can chemically bind and effectively immobilize hazardous wastes, contributing to the environmental protection efforts. ${ }^{8}$

So far large-scale applications and commercialization of AAMs are still scarce because of several unsolved problems. The durability of AAMs is one matter of widespread concern as the performance of AAMs under aggressive environments has been observed to vary from being unacceptable to excellent. ${ }^{9-11}$ Therefore, an improved understanding of the durability properties of AAMs is highly important for extending its application. Secondly, durable material will avoid the heavy financial burdens from the maintenance work and also reduce environmental impacts by conserving resources used for repair and replacement. Although the past decades have witnessed considerable research efforts devoted to AAMs, to our knowledge, there is no systematic review of the durability of this system from material to structure. 


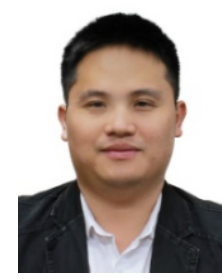

\section{Wengui Li}

Dr. Wengui Li is a Lecturer and an ARC DECRA Fellow in School of Civil \& Environmental Engineering at University of Technology Sydney, Australia. His research interests include recycled concrete, self-healing and self-sensing concrete, concrete nanotechnology, geopolymer concrete, durability under extremes, fire resistance, prefabricated structures and sustainable construction materials.

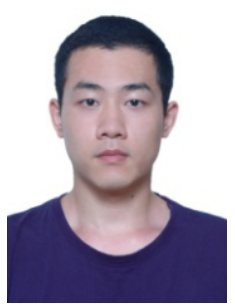

\section{Zhuo Tang}

Mr Zhuo Tang is a Ph.D Candidate in School of Civil \& Environmental Engineering at University of Technology Sydney, Australia. His research interests include geopolymer composites and recycled concrete.

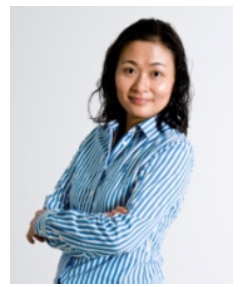

\section{Vivian W. Y. Tam}

Professor Vivian W. Y. Tam is a Professor at School of Computing, Engineering and Mathematics, Western Sydney University, Australia. Her research interests are in the areas of environmental management in construction and sustainable development.

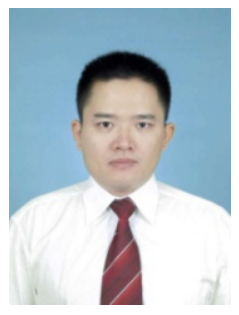

\section{Xinyu Zhao}

Dr Xinyu Zhang is an Associate Professor in State Key Laboratory of Subtropical Building Science at South China University of Technology, China. His research interests include recycled concrete, steel-concrete composites and fire resistance of concrete.

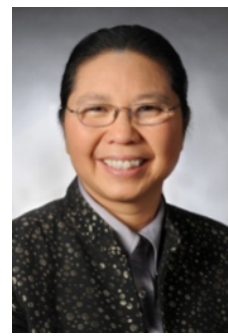

\section{Kejin Wang}

Professor Kejin Wang is currently a Willison Engineering Professor at the Department of Civil, Construction, and Environmental Engineering in Iowa State University, USA. Her research interest and areas of expertise include rheology, chemistry, microstructure, multi-scale characterization, and durability of cement and concrete materials. 
Therefore, this review provides a critical review of the durability performance of AAMs covering the levels of material and structure. On the material one, the mass transport properties largely governing the durability of AAMs are studied. In addition, the durability performances of AAMs are examined when subjected to physically and chemically induced deterioration respectively. The effects of major factors such as the composition of source materials, nature of chemical activators, curing regime and exposure condition are exhaustively deliberated. On the structural one, the performances of structures and products based on AAMs subjected to aggressive environments are presented. Finally, conclusions and recommendations are proposed for providing a basis for further studies on the durability performance of AAMs.

\section{Methodologies}

The durability is by nature a multilevel problem, as durability design has different meanings for the structural part and the material part. This study attempts to treat the durability of AAMs in an integrated fashion, by investigating the materials and structural behaviors simultaneously. To align with this target, the literature sourcing was conducted extensively and with special attention to the publications in the last decade (2008-2018)

At the material level, the mass transport properties of AAMs were reviewed at first. Then, this work reviewed the durability performance of AAMs under physically induced deterioration and chemically induced deterioration. Freeze-thaw cycle, and fire or elevated temperature exposure were considered as two major reasons for physically induced deterioration. Chemically induced deterioration includes acid corrosion, sulfate attack, carbonation, and alkali-aggregate reaction. The findings are categorized based on the studied factors such as the source material, chemical activator, curing regime, additive and exposure condition. Then a comparison was conducted to examine the influences of these factors on the durability performances. While consistent conclusions derived from different references were considered as a firm base and reasonable interpretation of these conclusions was proposed with efforts, contradictory results or findings from different publications were also highlighted to raise awareness for further research. On the topic of structural performance, the review focused on the performance of structures and products based on AAMs under aggressive environments including reinforced alkali-activated concrete beams, slabs, box culvert, and alkali-activated mortar coating or repairing. Finally, the review concludes with a concise summary of the key findings and the recommended research directions in the future.

\section{Mass transport properties}

Most deterioration processes involve the penetration of chemical substances (ions or molecules) through the unavoidable holes into material. Water, as a solvent carrying ionic or molecular species such as chloride, sulfate and carbon dioxide, penetrates into AAMs, and then interacts with the reaction products of AAMs or embedded steel reinforcing, causing structural deterioration. This is especially true for reinforced concrete, as the degradation of embedded steel reinforcing is the main cause of the structural collapse, not the binder itself. The ingression of aggressive agents promotes the corrosion of reinforcing and results in the reduction in loading capacity or even structural failure. ${ }^{12}$ Therefore, the durability of AAMs largely depends on its ability to resist penetration of water and other aggressive species. The following section will discuss the factors influencing the transportrelated properties of AAMs.

Chemical activator plays a vital role in the transport properties of AAMs. The commonly used chemical activators in producing AAMs

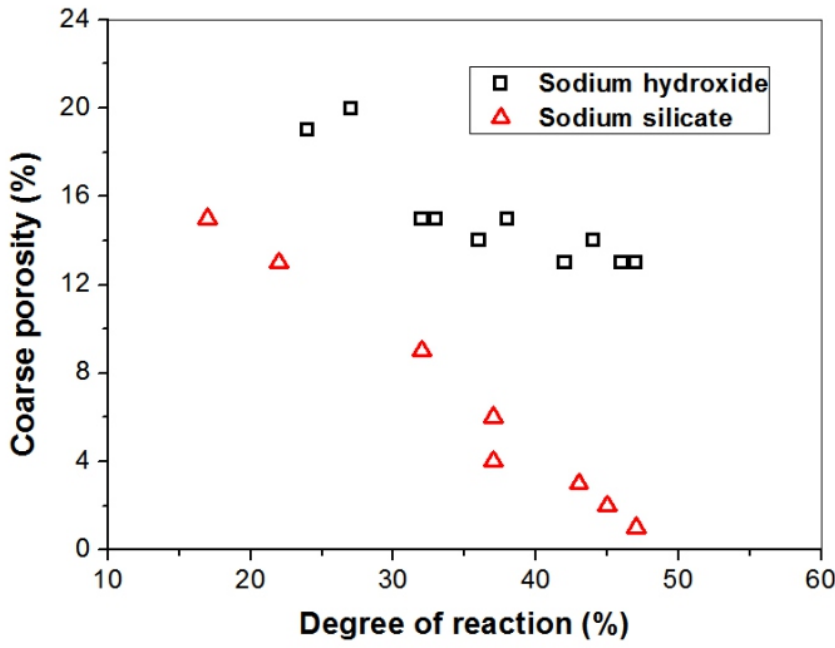

Fig. 1 Coarse porosity 0.05 to $5 \mu \mathrm{m}$ under different degrees of hydration of slag pastes activated with sodium hydroxide and sodium silicate-adapted from Ben Haha, et al. ${ }^{13}$

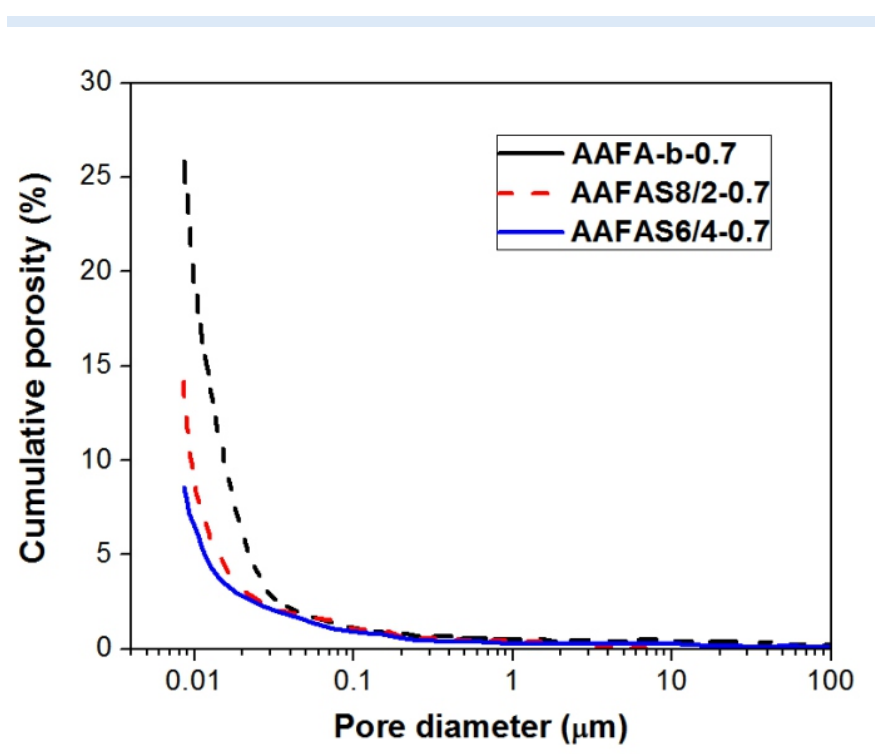

Fig. 2 Cumulative pore size distributions for AAMs with different ratio of fly ash/slag (10/0, 8/2 and 6/4) and slag blending Portland cement pastes-adapted from Zhu, et al. ${ }^{18}$

are sodium silicate and sodium hydroxide. Ben Haha et al. ${ }^{13}$ reported that sodium silicate gave a denser microstructure, in comparison with sodium hydroxide having the same alkali content. Clear differences can be pointed out from the different relationships between the degree of reaction and the coarse porosity in slag pastes activated by sodium hydroxide and sodium silicate, as shown in Fig. 1. It is explained that for the systems activated with sodium hydroxide, the fast initial reaction leads to unevenly distributed hydration products. Even though the reaction continues for a period, the improvement of coarse porosity is limited. While in the systems activated by sodium silicate, the reaction proceeded slowly, and therefore, there is sufficient time for reaction products to diffuse and precipitate, resulting in well-compacted microstructures. ${ }^{13}$ Additionally, silica in the activator of sodium silicate can react with the aluminum species dissolved from the source material and then incorporate into the formation of aluminosilicate gels. ${ }^{14}$ 
Table 1 Effects of modulus and alkali concentration on the transport properties of AAMs.

\begin{tabular}{|c|c|c|c|c|}
\hline Literatures & $\mathrm{Na}_{2} \mathrm{O}$ percent & $\mathrm{SiO}_{2}$ percent & Ms & Primary findings \\
\hline Škvára et al. ${ }^{121}$ & $6,8,10$ & 10 & $1.6,1.4,1.0$ & Higher alkali content resulted in a well-compact structure \\
\hline Thokchom et al. ${ }^{122}$ & $5.0,6.5,8.0$ & 6.5 & $1.3,1.0,0.8$ & \\
\hline Wang et al. ${ }^{15}$ & $2.4,3.6,4.8,6.0$ & 6.3 & $2.7,1.8,1.4,1.1$ & \\
\hline Law et al. ${ }^{123}$ & 7.5 & $9.5,7.5,5.5$ & $1.25,1.00,0.75$ & $\begin{array}{l}\text { Increased activator modulus at constant alkali content } \\
\text { provided denser structure }\end{array}$ \\
\hline $\begin{array}{l}\text { Fernández -Jiménez } \\
\text { and Palomo }\end{array}$ & $7.7 ; 5.6$ & $9.2 ; 7.1$ & 1.2 & $\begin{array}{l}\text { Increased alkali content at constant modulus led a } \\
\text { compacted structure }\end{array}$ \\
\hline Ma et al. ${ }^{124}$ & $9.3,8.1,6.2$ & $3.0,6.0,9.0$ & $1.0,0.8,0.7,0.3$ & $\begin{array}{l}\text { Higher alkali content had a more significant influence on } \\
\text { densifying the microstructure than silica content. }\end{array}$ \\
\hline Shi and $\mathrm{Li}{ }^{125}$ & $2.0 ; 3.0$ & $\begin{array}{l}4.8,2.9,1.0,0 \\
7.3,4.4,1.5,0\end{array}$ & $2.5,1.5,0.5,0$ & 1.5 is the optimum modulus for dense and compacted structure \\
\hline
\end{tabular}

Moreover, the manifestation of the formed matrix varies with modulus (Ms) and alkali concentration. Table 1 summarizes the effects of modulus and alkali concentration on the transport properties of AAMs. This can be inferred from the literature that excessive alkali concentration leads to premature coagulation, ${ }^{15}$ while low alkali content is insufficient to stimulate an effective chemical activating. ${ }^{16}$ Meanwhile, excess silica would hinder water evaporation and disrupt the formation of networks. ${ }^{17}$ Any of such situations would end up with a poor microstructure and consequently inferior transport properties. Therefore, the determination of proper modulus and alkali concentration of activator solution for activating different source material is of paramount importance.

The reaction products exhibit disparate transport performance when using different source material. Zhu et al. ${ }^{18}$ investigated the pore structure of alkali-activated fly ash/slag pastes. As shown in Fig. 2, the inclusion of slag in alkali-activated fly ash pastes reduced the cumulative porosity significantly. This trend is consistent with the results observed by Zhang et al. ${ }^{19}$, Zhang et al. ${ }^{20}$ and Ismail et al. ${ }^{12}$. The different microstructures of the specimens with different proportions of fly ash and slag are correlated with the distinct nature of the forming gel. A denser calcium silicate hydrate gel (C-A-S-H) with high pore tortuosity dominates the microstructure of activated slag or other highcalcium systems. ${ }^{21}$ However, the incorporation of fly ash or other lowcalcium precursor promotes the formation of alkali aluminosilicate type gels (N-A-S-H) which are porous. ${ }^{22}$ As for the AAMs formed from lowcalcium precursors, or namely geopolymer, Silva et al..$^{23}$ observed that the microstructures with higher $\mathrm{SiO}_{2}$ to $\mathrm{Al}_{2} \mathrm{O}_{3}$ molar ratio were denser and more homogeneous. However, when the molar ratio exceeded a certain value, too much silica content negatively affected both depolymerization and polymerization, thus restrained the development of the microstructure and increased the porosity, which is consistent with the results when there was excessive content of silica in activator. ${ }^{24}$ Additionally, the variation of the fineness of source materials has a significant influence on the pore structure of AAMs. Chotetanorm et al. ${ }^{25}$ compared the performance of alkali-activated mortars based on high calcium bottom ash with various fineness (median particle sizes of 16 , 25 and $32 \mu \mathrm{m}$, respectively). The test results exhibited that the lowest rate of sorptivity and percentage of large pores were found in specimens prepared with fine bottom ash. It is because that the grinding increases the surface area of particles, which results in higher degree of leaching of alumina and silica species and therefore higher degree of geopolymerization. ${ }^{26}$ On the other hand, coarse raw materials require more liquid to achieve suitable workability, compared with fine raw materials. The additional activator or water would cause high porosity or slow down the degree of dissolution and reaction, and consequently high permeability. ${ }^{27}$

In addition to the adjustment in chemical activator and source material, the curing system plays a crucial role in meliorating the transport properties of AAMs. It was found that part of raw material remained unreacted even after a long curing period. ${ }^{26}$ Elevated curing temperature can be utilized to reduce the amount of unreacted source material, and therefore, poly-condensation of aluminosilicate gel is presumed to result in the formation of additional reaction productions, which bond unreacted particles or fill cracks and voids. ${ }^{28}$ Table 2 summarizes the effect of the curing regime on the transport properties of AAMs. It is concluded that increasing curing temperature is in favor of increasing dissolution, hydrolysis and condensation in AAMs, but the excessive increase in temperature or heat treatment period brings less benefit or even impedes reaction processes, which in turns weakens the properties of AAMs. Moreover, different types of curing regime could be employed, such as calcination, ${ }^{29}$ microwave-assisted curing, ${ }^{30}$ steam curing, and autoclave curing, ${ }^{31}$ for maximizing the performance of AAMs as shown in Table 2.

As OPC-based concrete modified by nano-sized additives exhibited better performance in durability ${ }^{32}$, researchers investigated the effects of nano-sized additives on the durability performance of AAMs, such as nano-silica, ${ }^{33,34}$ nano-alumina, ${ }^{33,34}$ nano- $\mathrm{TiO}_{2},{ }^{35}$ nano-clay, ${ }^{36}$ and carbon nano-tubes. ${ }^{37}$ Some nano-sized additives can act as a source of elements such as silica, alumina, and calcium to provide element equilibrium in AAMs, which greatly enhances its durability performance. ${ }^{10,33}$ In addition, the filling effect and the increased reactivity brought by nanoparticles enhance the microstructure properties. But when excess content of nano-sized additives was incorporated, it was reported that agglomeration of nanoparticles led to less dense structures with a 
Table 2 Effect of curing regime on the transport properties of AAMs.

\begin{tabular}{|c|c|c|c|}
\hline $\begin{array}{l}\text { Precursor } \\
\text { Fly ash based }\end{array}$ & Curing regime & Main Indicator & Primary finding \\
\hline Noushini and Castel $^{126}$ & $\begin{array}{l}23,60,75 \text { or } 90^{\circ} \mathrm{C} \text { for } \\
8,12,18 \text { or } 24 \mathrm{~h} .\end{array}$ & $\begin{array}{l}\text { Pore distribution, } \\
\text { resistivity }\end{array}$ & $\begin{array}{l}\text { Curing temperature and curing period should exceed } 75^{\circ} \mathrm{C} \text { and } \\
18 \text { hours }\end{array}$ \\
\hline Nazari and Sanjayan ${ }^{34}$ & $\begin{array}{l}30,45,60 \text { or } 70^{\circ} \mathrm{C} \text { for } \\
24 \mathrm{~h}\end{array}$ & $\begin{array}{l}\text { Carbon dioxide } \\
\text { permeability }\end{array}$ & The permeability values increase with increased temperature \\
\hline \multirow[t]{2}{*}{ Sindhunata et al. ${ }^{127}$} & 30,50 or $75^{\circ} \mathrm{C}$ for 24 & $\begin{array}{l}\text { Pore distribution, } \\
\text { pore surface }\end{array}$ & $\begin{array}{l}\text { An increase in mesopore volume, surface area with elevating the } \\
\text { curing temperature. }\end{array}$ \\
\hline & $\mathrm{h}$ or $48 \mathrm{~h}$ & & \\
\hline Chindaprasirt et al. ${ }^{28}$ & $\begin{array}{l}5 \text { min microwave } \\
\text { heating followed by } \\
\text { oven curing at } 60^{\circ} \mathrm{C}\end{array}$ & $\begin{array}{l}\text { Microstructure } \\
\text { micrographs }\end{array}$ & $\begin{array}{l}\text { The microwave radiation can shortened the required time of heat } \\
\text { curing and enhanced the geopolymerization }\end{array}$ \\
\hline \multicolumn{4}{|l|}{ Slag based } \\
\hline Ravikumar et al. ${ }^{128}$ & $\begin{array}{l}60 \text { or } 75^{\circ} \mathrm{C} \text { for } 24 \text { or } \\
48 \mathrm{~h}\end{array}$ & Porosity, & Porosity decreases with increases in temperature and duration \\
\hline Gebregziabiher et al. ${ }^{129}$ & $\begin{array}{l}\text { Moist-cured at } 23^{\circ} \mathrm{C} \\
\text { or heat-cured at } 50^{\circ} \mathrm{C}\end{array}$ & $\begin{array}{l}\text { Microstructure } \\
\text { micrographs }\end{array}$ & $\begin{array}{l}\text { Effect of curing temperature on the microstructure depends on } \\
\text { the type of activators }\end{array}$ \\
\hline Aydın and Baradan ${ }^{31}$ & $\begin{array}{l}\text { Steam curing at } 100^{\circ} \mathrm{C} \\
\text { or autoclaved at } 210^{\circ} \mathrm{C}\end{array}$ & $\begin{array}{l}\text { Microstructure } \\
\text { micrographs }\end{array}$ & Autoclave cured specimens display more compacted structure \\
\hline \multicolumn{4}{|l|}{ Metakaolin based } \\
\hline Rovnaník ${ }^{130}$ & $\begin{array}{l}40,60 \text { or } 80^{\circ} \mathrm{C} \text { for } 1,2 \\
\text { or } 3 \mathrm{~h}\end{array}$ & Pore distribution & $\begin{array}{l}\text { Mean pore size decreases with ageing. } \\
\text { Elevated temperature leads to the formation of larger pores and } \\
\text { increased cumulative pore volume. }\end{array}$ \\
\hline \multicolumn{4}{|l|}{ Slag/fly ash blends based } \\
\hline Sugama et al. ${ }^{63}$ & $\begin{array}{l}\text { Autoclave curing for } \\
24 \mathrm{~h} \text { at } 100,200 \text { or }\end{array}$ & Porosity & $\begin{array}{l}\text { Porosity decreases with elevated temperature from } 100 \text { to } 200^{\circ} \mathrm{C} \text {, } \\
\text { the effect of temperature from } 200 \text { to } 300^{\circ} \mathrm{C}\end{array}$ \\
\hline
\end{tabular}

negative impact on durability. ${ }^{34,37}$

\section{Physically induced deterioration}

Physical processes that can lead to the deterioration of AAMs mainly include free-thaw cycles, fire or elevated temperature exposure, cavitation, abrasion, and exfoliation. Those conditions can depress the performance of AAMs and threaten the safety of structures. Thus, a clear understanding of the characteristics of AAMs under physical attacks is highly critical. The following section presents an overview focusing on various effects such as chemical activators, source materials, and curing regime towards the durability performance of AAMs under two major physical deterioration mechanisms, i.e., freezethaw cycles and fire or elevated temperature exposure.

\subsection{Freeze-thaw cycles}

Besides acting as a medium by which aggressive agents invade AAMs, water itself can produce pressure in the pores of AAMs as it expands when freezing. The cavity will expand and eventually crack when the tensile strength of AAMs cannot resist the evolved pressure. After continuous freeze-thaw cycles, AAMs may eventually scale and crumble due to the accumulative effect.

As a general finding, dense structures with small capillary porosity and trapped permeability make it arduous for freezable water to penetrate into. ${ }^{38}$ Therefore, the improved mass transport properties always accompany with higher freeze-thaw resistance as little water can penetrate into. For instance, Shahrajabian and Behfarnia ${ }^{39}$ studied the properties of alkali-activated slag concrete containing nano-particles including nano-silica, nano-alumina, and nano-clay. The test results indicated that the freeze and thaw resistance of alkali-activated slag concrete containing nano-particles were considerably improved, as result 
of a more compacted microstructure. It was also concluded that nanosilica and nano-clay, respectively, performed better than the nanoalumina in improving the durability of alkali-activated slag concrete subjected to freeze and thaw cycles.

Cai et al. ${ }^{40}$ studied the freeze-thaw resistance of alkali-activated slag concrete and investigated the effects of activator solutions to slag ratio, slag content, and sand ratio on the freeze-thaw resistance and pore characteristic. It is found that the freeze-thaw resistance had a good correlation with air bubble spacing coefficient. The study also showed that the significance of different factors for the alkali-activated slag concrete frost resistance decreased as solution/slag ratio, slag content, and sand ratio. Reduced solution/slag ratios and increased slag contents led to better performance, while the sand content had very little influence on the freeze-thaw performance.

Air-entraining agent is usually used to improve freeze-thaw capability and prolong service life in conventional concrete. Shi ${ }^{41}$ reported that the incorporation of air-entraining agents allowed alkaliactivated slag paste to resist 300 cycles of freeze-thaw and retain over $90 \%$ of their elastic modulus, while the specimens without air-entraining agents were unable to survive during the test as they underwent complete degradation after only 100-120 cycles. Although air-entraining agent usually increases the porosity of material, the refined bubble network can improve freeze-thaw resistance because it can cut the water paths and provide additional spaces for ice to expand, which in turn reduces the hydraulic pressure to prevent cracking. A similar phenomenon was observed in alkali-activated fly ash/slag concrete incorporated with micro-encapsulated phase change material (MPCM), that the addition of MPCM provided an excellent resistance against freeze-thaw cycles with a minor reduction of the compressive strength. ${ }^{42}$ It was explained that air voids and gaps between the microcapsules and the surrounding concrete provide free expansion space for water when it freezes, thereby reducing the frost-induced stress. However, Rostami and Brendley ${ }^{43}$ observed that air-entrained alkali-activated fly ash concrete exhibited slight scaling while the non-air-entrained specimens demonstrated no scaling, after 40 freeze-thaw cycles. This was because the compressive strength of air-entrained specimens was $10-30 \%$ lower than that of the non-air-entrained specimens. Therefore, the amount of air-entraining agent should be further optimized for ensuring that the strength remains acceptable.

\subsection{Elevated temperature or fire exposure}

Elevated temperatures pose a risk of destruction for most cementitious material. For instance, concrete based on OPC begins to disintegrate when the temperature rises above $300{ }^{\circ} \mathrm{C}$ because of the chemical and physical changes internally. There are several studies reporting that AAMs performed better than OPC at elevated temperatures for its inorganic framework, and AAMs with superior high-temperature tolerance could be obtained by refined selection of ingredients and mixing design. ${ }^{44,45}$

AAMs activated by different alkali solutions exhibit different characteristics when subjected to fire or elevated temperature. Karahan and Yakupoğlu ${ }^{46}$ examined the behaviors of alkali-activated slag mortar activated by sodium hydroxide, sodium carbonate, and sodium silicate, with the same content of alkali, after exposure to the temperature of $1000{ }^{\circ} \mathrm{C}$. Fire resistance of sodium hydroxide-activated specimens was better than others. Bakharev ${ }^{47}$ compared the thermal stability of fly ash based geopolymers material activated by potassium-based and sodiumbased alkaline activator upon firing at $800-1200{ }^{\circ} \mathrm{C}$, and showed that the specimen prepared from potassium containing activators exhibited better thermal stability than the specimen prepared from sodium containing activators. Panias et $a l^{48}$ pointed out that the potassium aluminosilicate system was more advantageous than the sodium aluminosilicate system for fire resistance applications, due to the potassium system with congruent melting points higher than $1693{ }^{\circ} \mathrm{C}$ in relation to the sodium system with substantially lower congruent melting points at $1526^{\circ} \mathrm{C}$.

Guerrieri and Sanjayan ${ }^{49}$ studied the behavior of alkali-activated fly ash/slag pastes when exposed to high temperature up to $800{ }^{\circ} \mathrm{C}$, and found that the high strength loss was associated with the specimens containing a high proportion of slag. This is attributed to the fact that the specimens with a high proportion of slag possessed low ductility, which had a lower capacity to accommodate the non-uniform thermal deformation. Recently, Pan et al. ${ }^{50}$ reported similar findings that fly ashbased specimens showed an increase in strength at $600{ }^{\circ} \mathrm{C}$ and the slagbased and fly ash/slag-based specimens exhibited worse hightemperature behavior. As shown in Fig. 3, a weak microstructure with a number of cracks is observed in the slag-based specimen and the specimen with $50 \%$ of fly ash and $50 \%$ of slag, in comparison with a dense morphology in the specimens mainly based on fly ash. It is because the AAMs based on fly ash have large numbers of small pores which facilitate the escape of moisture when heated, thus causing minimal damage to the matrix..$^{51}$ Moreover, it was reported that high calcium content in slag has a detrimental effect on thermal properties of AAMs. ${ }^{44,48}$ At higher calcium contents, the specimens were more susceptible to high temperature due to the relatively low melting point. The addition of $\mathrm{CaO}$ changed the system's stoichiometry forming less refractory compounds that decreased the liquidus temperature and caused a big gap between the liquidus and the solidus temperatures. ${ }^{48}$

Rickard et $\mathrm{al}^{52}$ found that the ratio of $\mathrm{Si}$ to $\mathrm{Al}$ in the glass of the fly ash strongly influenced the thermal performance of the geopolymers. Geopolymers synthesized from fly ashes with a high ratio of $\mathrm{Si}$ to $\mathrm{Al}$ $(>5)$ exhibited compressive strength gains and greater dimensional stability upon exposure to $1000{ }^{\circ} \mathrm{C}$, whereas geopolymers synthesized from fly ashes with a low ratio of $\mathrm{Si}$ to $\mathrm{Al}(<2)$ exhibited strength losses and reduced dimensional stability upon high-temperature exposure. Similar results were observed in metakaolin-based geopolymer materials by Kong et $a l .^{53}$, who reported that the specimens with high $\mathrm{Si} / \mathrm{Al}$ ratio underwent lower strength reduction when exposed to elevated temperature as compared with the specimens with low $\mathrm{Si} / \mathrm{Al}$ ratio.

The inclusion of aggregate also affects the thermal properties of AAMs. Kong and Sanjayan ${ }^{54}$ found that the alkali-activated fly ash paste specimens exhibited strength increase of about 53\% after being subjected to the temperature of $800{ }^{\circ} \mathrm{C}$ for $1 \mathrm{~h}$, while the concrete specimens with identical alkali-activated binder formulations decreased in strength by up to $65 \%$ after the same high-temperature exposure. The study also showed that the aggregate steadily expanded under high temperature, reaching about $2.0 \%$ expansion at $800{ }^{\circ} \mathrm{C}$, while the alkaliactivated matrix showed a contraction of about $2 \%$ at $800{ }^{\circ} \mathrm{C}$. Therefore, the mismatch between thermal contraction of binder and expansion of aggregate caused cracking and strength degradation of alkali-activated concrete. ${ }^{55}$ The properties of composite material based on AAMs with different types of aggregate were investigated by Rovnaník and Dufka ${ }^{56}$, , and Rashad ${ }^{57}$. It was found that using proper aggregate could mitigate the deterioration of AAMs at high temperatures. For instance, the use of expanded perlite as fine aggregate in the geopolymer mortars resulted in much higher thermal insulation and better fire resistance than silica sand aggregate. ${ }^{57}$ A utilization of chamotte as an aggregate in the AAMs composites brought several benefits compared to quartz sand, including the improved mechanical parameters when exposed to elevated temperatures. ${ }^{56}$ In addition, aggregate size governs the behaviors of AAMs at elevated temperatures. It was observed that larger aggregate 


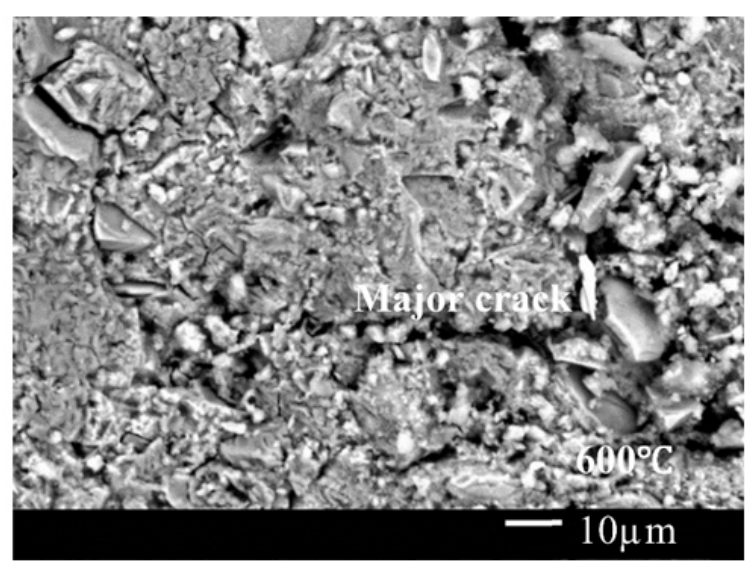

(a) $100 \%$ slag

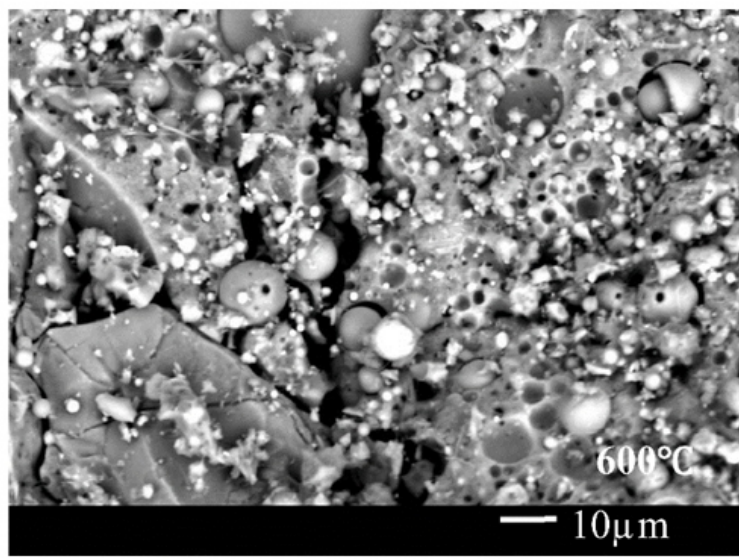

(c) 90 wt. \% fly ash/10 wt.\% slag

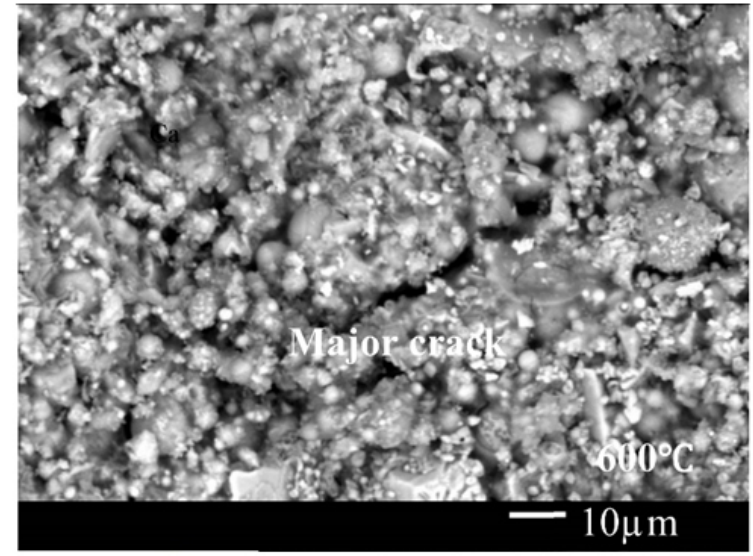

(b) 50 wt. $\%$ fly ash $/ 50$ wt. $\%$ slag

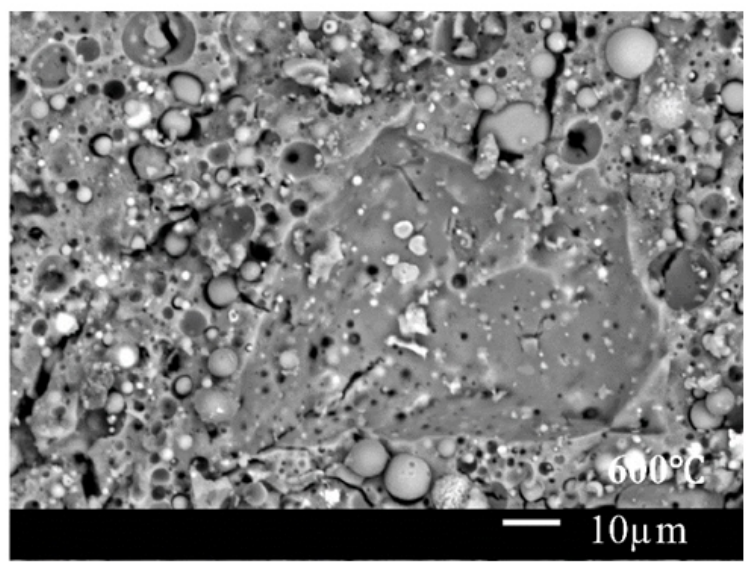

(d) $100 \%$ fly ash

Fig. 3 BSE images of alkali-activated fly ash/slag pastes after exposure to $600{ }^{\circ} \mathrm{C}$-adapted from Pan, et al. ${ }^{50}$

resulted in excellent strength performances of alkali-activated concrete at elevated temperatures. ${ }^{58}$

\section{Chemically induced deterioration}

Although the compact microstructure with less transport of aggressive agents outside can reduce the invasion and penetration of corrosive substances, it cannot fully guarantee the durability of AAMs in practice. ${ }^{10}$ The durability performance of AAMs is also highly influenced by the chemical stability or the tolerance of the material itself. ${ }^{59}$ When AAMs are subjected to aggressive environments, chemical agents react with or even dissolve the cementitious matrix, resulting in the loss of the integrity or cohesion of the matrix as well as the formation of some new compounds that brings side effects such as expansion." ${ }^{90}$ Depending on the types and nature of aggressive substances, they can result in different kinetics reactions and deterioration processes. The most commonly observed chemicallyinduced deteriorations include acid corrosion, sulfate attack, carbonation, and alkali-aggregate reactions. Hence, the factors that influence the performance of AAMs subjected to these chemically induced deteriorations are discussed below.

\subsection{Acid corrosion}

Inorganic acids, for example, sulfuric acid are highly corrosive towards construction materials whether based on OPC or AAMs. Exposure to acids always leads to the severe degradation of the binding phases, and consequently, the decay of the mechanical strength. Many researchers claim that the superior acid resistance is one of the advantages of AAMs over OPC. ${ }^{11,59,60}$ Regardless of OPC or AAMs, the degradation of acid attack on binders is mainly through ion exchange reactions, such as the substitution of alkali cations by hydronium or hydrogen ions, and the dealumination of gel structure. ${ }^{61}$ This leads to the formation of novel compounds such as siliceous polymers and zeolites, which can leach out and then destroy the integrity of the materials in-situ. ${ }^{61}$

As mentioned above, the inclusion of slag or other high-calcium source materials can reduce pore size and porosity of AAMs, which lessens the ingression of aggressive substances. Nevertheless, it was reported that C-A-S-H gel formed in the high-calcium system was more susceptible to acidic attack, while N-A-S-H gel formed in the lowcalcium system is less sensitive for the stability of its cross-linked structure. ${ }^{62}$ Sugama et al. ${ }^{63}$ studied the effect of fly ash content $(0-50 \%)$ on the acid resistance of alkali-activated slag/fly ash blends paste that slag was the main component. The specimens containing a larger amount of fly ash exhibited less weight loss after immersion in acid solutions, reflecting a good acid resistance. Lee and Lee ${ }^{64}$ investigated the effect of slag content (from 0 to $50 \%$ ) on the stability of alkali- 


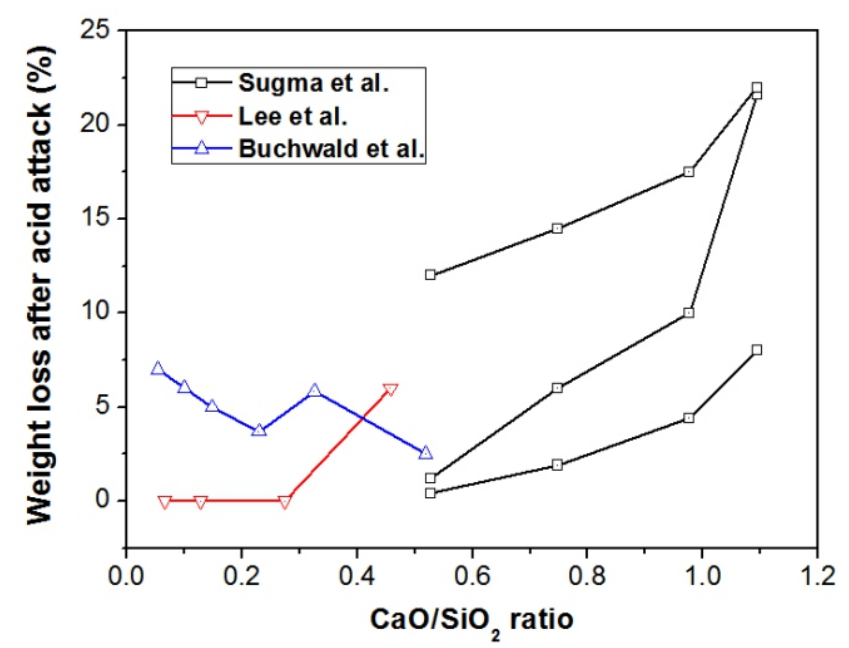

Fig. 4 Weight loss after acid attack as a function of $\mathrm{CaO} / \mathrm{SiO}_{2}$ ratioadapted from Sugama, et al. ${ }^{63}$, Lee and Lee ${ }^{64}$, Buchwald, et al. ${ }^{65}$

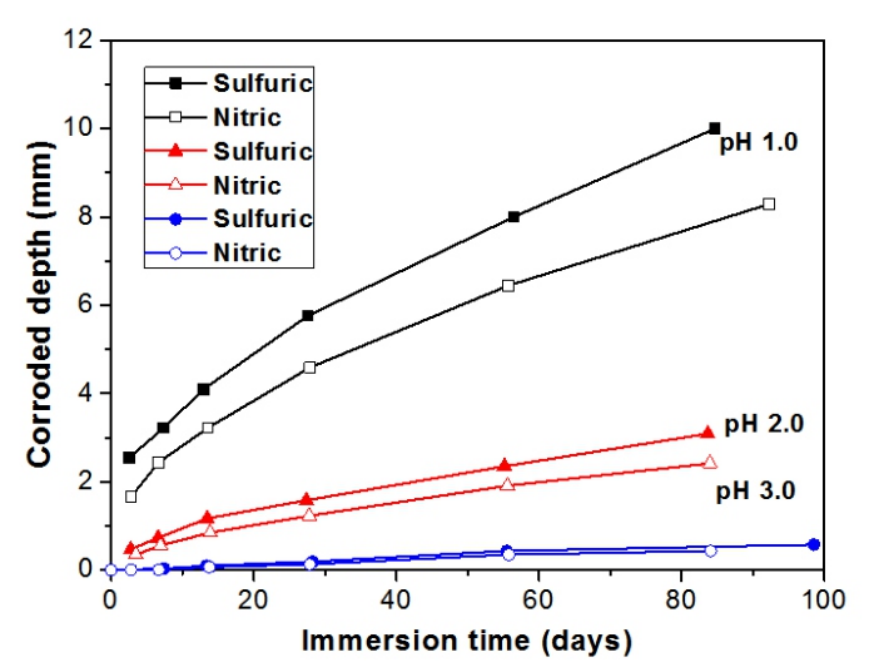

Fig. 5 Corrosion depths for fly ash-based alkali-activated specimens immersed in sulfuric and nitric acid solution maintained at $\mathrm{pH}$ values of 1.0, 2.0 and 3.0-adapted from Lloyd, et al. ${ }^{68}$

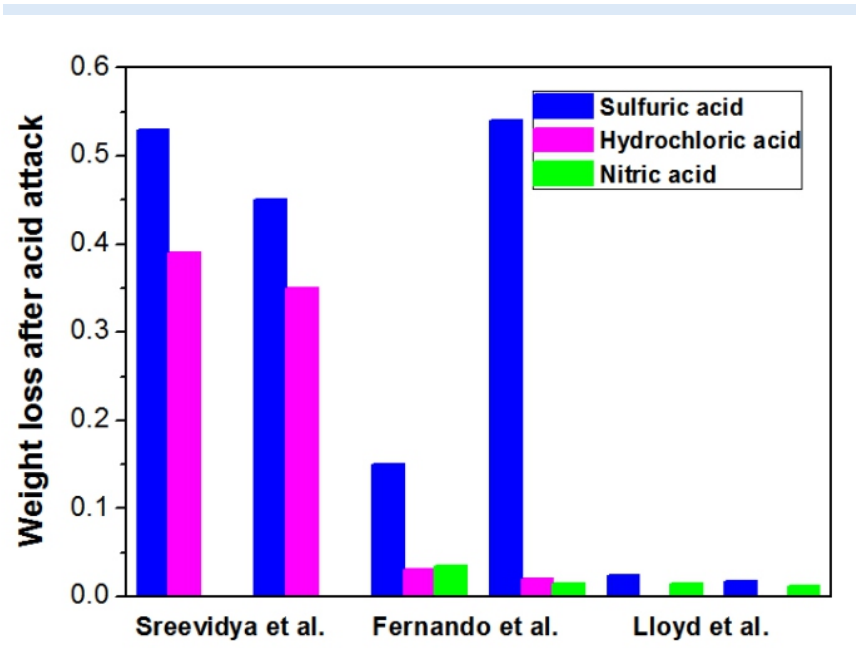

Fig. 6 Weight loss of AAMs subjected to different acid solutions at a given $\mathrm{pH}$ value or concentration-adapted from Lloyd, et al. ${ }^{68,}$ Fernando, et al. ${ }^{70,}$ Sreevidya, et al. ${ }^{131}$ activated fly ash/slag paste under acid attack. With the increasing content of slag in the mixture, the specimens were expected to more susceptible to acidic environment, as the increased content of C-A-S-H gel and the decreased content of N-A-S-H gel. However, in this test, the alkali-activated fly ash/slag paste specimens with $10 \%$ and $50 \%$ of slag exhibited less strength loss than the specimens with $30 \%$ slag content. It was suggested that the high acid resistance in the specimens with 50\% slag content was due to the denser matrix with fewer permeable voids, while in the paste with lower slag content was due to the inherent high resistance of N-A-S-H gel to chemical attack. It can be seen from Fig. 4 that an appropriate ratio of $\mathrm{CaO}$ to $\mathrm{SiO}_{2}$ can provide alkali-activated fly ash/slag materials with a better acid resistance, and the ratio of $\mathrm{CaO}$ to $\mathrm{SiO}_{2}$ is basically controlled by the ratio between slag and fly ash in the blends. ${ }^{63-65}$ Therefore, further attention needs to be focused on figuring out the optimum ratio in blends to achieve a good performance in physical permeability and chemical stability simultaneously, and thereby better acid resistance.

Sodium silicate seems to be the most effective activators for AAMs as it promotes the formation of the lowest porosity and the finest pore structure. ${ }^{13}$ However, another interesting phenomenon was evidenced by Bakharev, ${ }^{61}$ who investigated acid resistances of fly ash based geopolymer materials activated with sodium hydroxide, sodium silicate, and a mixture of potassium hydroxide and sodium hydroxide solutions. The result showed that geopolymer activated with sodium hydroxide possessed the best acid resistance. Specifically, the strength losses of specimens activated by sodium hydroxide were $45 \%$ and $17.5 \%$, during immersion in acetic and sulfuric acid for 6 months, but the specimens activated by sodium silicate solutions performed with $60 \%$ and $82 \%$ strength loss after only 5-month immersion in acetic and sulfuric acid, respectively. It is because that the production of AAMs activated by sodium hydroxide is more crystalline, and with the increasing degree of crystallinity, AAMs are more stable in aggressive environments.

The acid resistance of AAMs is not only dependent on their chemical properties, but also on the parameters of the exposure environment. Although the resistance of AAMs to aggressive acidic environments has been investigated widely, the absence of unified test specifications has led to the use of different types or concentrations of acid solutions. ${ }^{66}$ It has been reported that the mechanism of corrosion was identical if the same acid is used, but the severity would increase with lower $\mathrm{pH}$ values or higher acid concentrations. ${ }^{67}$ Lloyd et al. ${ }^{68}$ investigated the depth of corrosion of fly ash geopolymer paste subjected to the attack of nitric and sulfuric acids with $\mathrm{pH}$ values of 1.0, 2.0 and 3.0. As shown in Fig. 5, the results confirmed the trend that the deterioration of geopolymer was much more serious under the attack of acid with a high concentration or a low $\mathrm{pH}$ value.

The previous studies also justified that the rate of corrosion was affected by the type of acid solution for the different strength of acid. ${ }^{68}$ Jiang et al. ${ }^{69}$ reported the results of alkali-activated slag mortar exposed to $5 \%$ solution of different acids within 6 months. Only slight changes were observed in the solution of citric acid, and moderate changes in nitric acid and hydrochloric acid solutions, while severe degradation was observed in sulfuric acid solution. As shown in Fig. 6, sulfuric acid has been proven to be more corrosive than another acid at a given $\mathrm{pH}$ value or concentration by many researchers. ${ }^{6870}$ However, some weak acids exhibit more aggressive impacts than strong acid at the same $\mathrm{pH}$ value because of buffering effects. ${ }^{71}$ For instance, Bernal et al. ${ }^{72}$ observed that an inappreciable change of compressive strength was found in alkali-activated slag mortars after exposure to inorganic acids. However, exposure to acetic acid reduced strength despite relatively high $\mathrm{pH}$ values. Besides the type and concentration or $\mathrm{pH}$ value of the acid solution, other parameters including the temperature, rate of acid 
replenishment, and alternate drying and wetting also influence the rate of corrosion. Therefore, it is of great importance to determine these parameters and the acidic environment in the tests.

\subsection{Sulfate attack}

Another problem related to the durability performance of AAMs is sulfate attack, which can be divided into internal chemical attack and external chemical attack. Internal chemical attack by sulfate is induced by sulfates already present in the composites such as an excess of gypsum, sulfate-rich aggregate, or contamination, and it can be avoided through proper screening. ${ }^{73}$ External chemical attack by sulfate is due to alkali metal present in environments such as the salinized soil, acid rain, and seawater. The process of external erosion is connected to the diffusion of sulfate into materials, which is influenced by the mass transport properties of materials and the reactivity between sulfate and material. There are limited studies on the sulfate resistance of AAMs reported in the literature. But based on the numerous investigations on the mechanism of sulfate attack on OPC where sulfate predominately reacts with the hydration products of the tri-calcium aluminate and calcium hydroxide to form an expansive crystalline product, it is believed that AAMs might exhibit higher sulfate resistance because of the absence of high-calcium phase. ${ }^{74}$

The durability performance of AAMs under sulfate attack is commonly examined by immersing in sodium sulfate or magnesium sulfate. Karakoç et al. ${ }^{75}$ studied the performance of AAMs subjected to magnesium sulfate solutions with different concentration $(3 \%, 5 \%$, and $7 \%$ by weight) for 6 months. After 6 months of soaking in magnesium sulfate solution, it was found that with the increases in magnesium sulfate content or exposure duration, the deterioration of alkali-activated concrete was more serious. The stability of the AAMs is also related to the cation type in the sulfate medium. Ismail et al. ${ }^{76}$ observed that alkaliactivated fly ash/slag paste after 3-month immersion in magnesium sulfate solution experienced extensive physical deterioration. However, specimens in sodium sulfate environment exhibited insignificant changes. As shown in Fig. 7, the X-ray diffractograms from different studies illustrate that the presence of magnesium leads to the decalcification or decomposition processes of the $\mathrm{Ca}$-rich gel phases and the precipitation of gypsum. In contrast, fewer changes in X-ray diffractograms upon exposure to sodium sulfate could be observed, coinciding with the better performance described in relevant studies. ${ }^{76,77}$ Thus, the process of sulfate attacks on AAMs strongly depends on the sulfate-associated cations, and magnesium sulfate is the most complex and influencing type, while sodium sulfate with the same concentration has limited impact on the microstructure of the material.

The effect of activator types on the stability of geopolymer material when immersing in sulfate environment was investigated by Bakharev ${ }^{74}$. Fly ash-based geopolymer pastes were activated by sodium hydroxide, sodium silicate, and a combination of potassium and sodium hydroxide solutions. The specimens were subjected to different sulfate solutions. Table 3 gives the strength changes of specimens after immersion in different sulfate solutions up to 150 days. It showed that the fly ash-based geopolymer prepared with sodium hydroxide, with 4$12 \%$ increased strength after immersed in sulfate solutions, were more stable than amorphous geopolymer activated by sodium silicate. ${ }^{61}$ However, different results were found in alkali-activated slag. Hasanein et al. ${ }^{78}$ compared the changes of the strength of alkali-activated slag
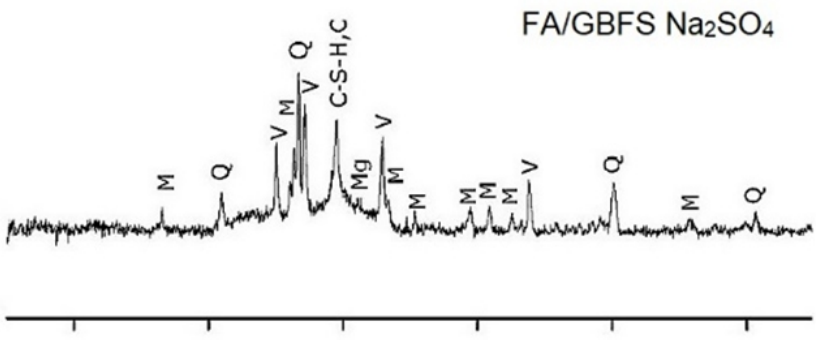

$\mathrm{FA} / \mathrm{GBFS} \mathrm{MgSO}_{4}$
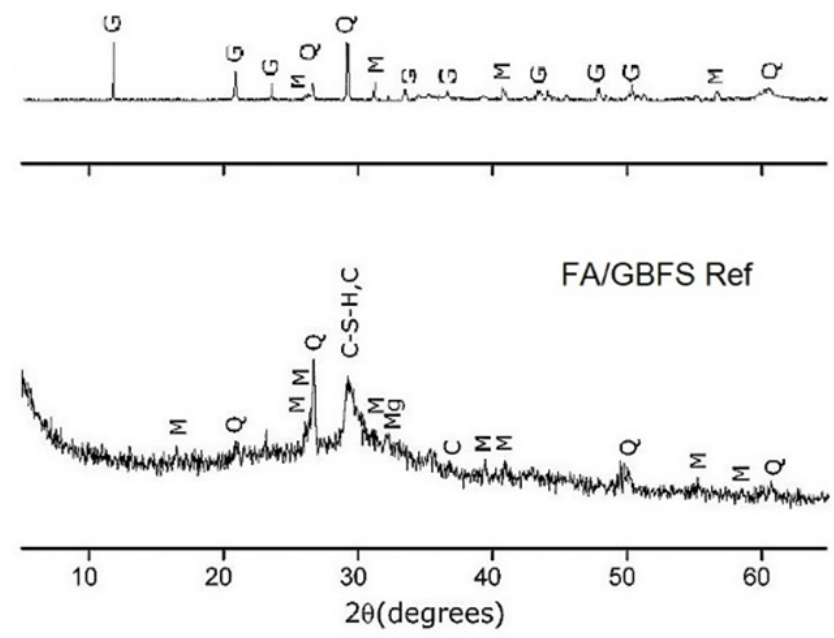

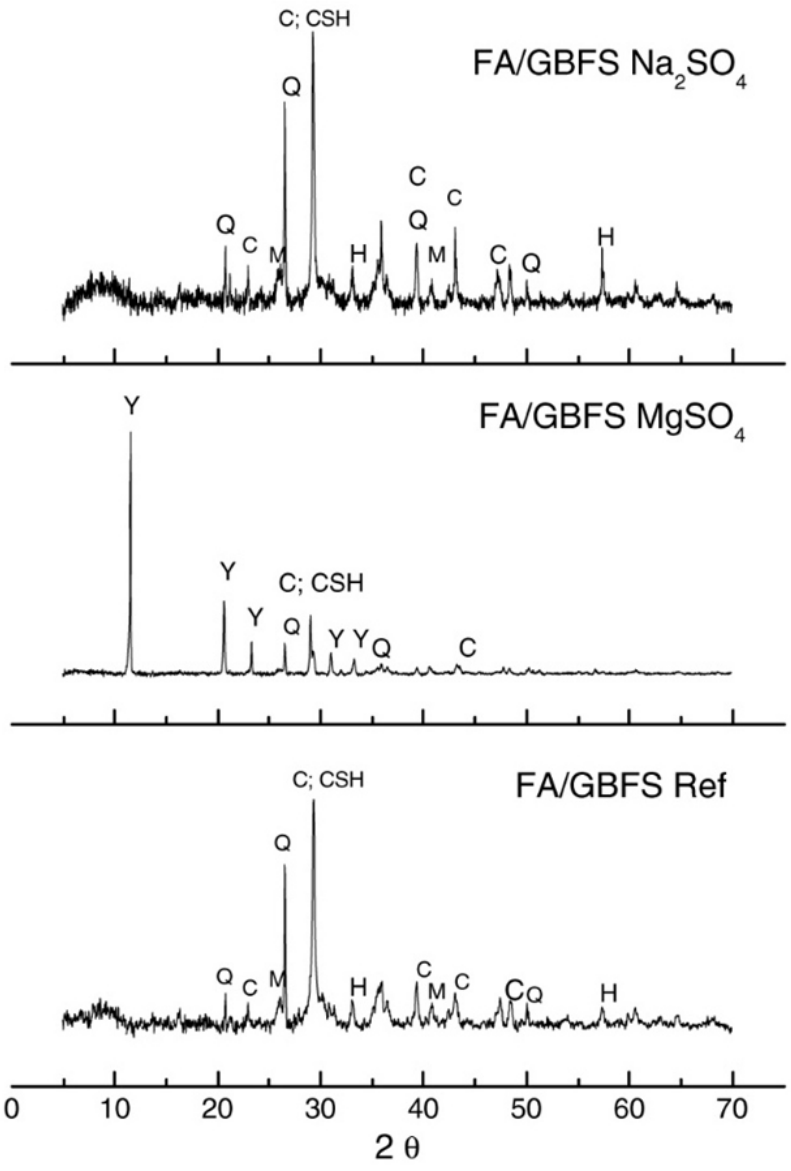

Fig. 7 XRD spectra of alkali-activated fly ash/slag pastes before and after sulfate attack (left from Ismail, et al. ${ }^{76}$, right from Valencia Saavedra, et al. ${ }^{77}$ 
Table 3 Strength variation of fly ash-based geopolymer materials alkalized by different activators after exposed to sulfate-adapted from Bakharev ${ }^{74}$.

\begin{tabular}{cccc}
\hline Type of activator & $\mathrm{Na}_{2} \mathrm{SO}_{4}$ solution & $\mathrm{MgSO}_{4}$ solution & $\mathrm{Na}_{2} \mathrm{SO}_{4}+\mathrm{MgSO}_{4}$ soluti on \\
\hline Sodium hydroxide & $+4 \%$ & $+12 \%$ & $+12 \%$ \\
Sodium silicate & $-18 \%$ & $-24 \%$ & $-4.5 \%$ \\
Sodium hydroxide and potassium hydroxide & $-65 \%$ & $+35 \%$ & $+10 \%$
\end{tabular}

pastes activated with 3 different chemical activators under magnesium sulfate attack. Chemical activators used involved sodium hydroxide with the content of $2 \%$ and $6 \%$, and a combination of $3 \%$ sodium silicate and 3\% sodium hydroxide in the mixture. After 6 months, the residual strength was $48 \%, 51 \%$ and $79 \%$ upon using $2 \%$ sodium hydroxide, $6 \%$ sodium hydroxide, and the mixed activator, respectively. Puertas et al. ${ }^{79}$ reported that water-glass activated or a mixture of water-glass and sodium hydroxide activated slag mortars presented high stability against sulfate, and slag mortar activated with sodium hydroxide was more sensitive to sulfate attack because expansive products such as gypsum or ettringite formed. It was suggested that the lower polymerization degree and higher $\mathrm{Ca} / \mathrm{Si}$ ratio in sodium hydroxide activated slag led to poor sulfate resistance, ${ }^{78}$ and the excess hydroxide ions facilitated the formation of ettringite. ${ }^{79}$

\subsection{Carbonation}

Carbonation resistance is an important part of durability performance. As carbon dioxide in the atmosphere diffuses through the pore structures, then reduces the alkalinity of pore solution and reacts with products of the cementitious matrix. This will cause the depassivation of the steel passive oxide film and lead to the loss of cohesion of the matrix. That is why carbonation is one of the most harmful degradation processes. It is possible to improve the performance of AAMs or to provide confident predictions in this area by developing a better understanding of this process and influencing factors. However, for AAMs, the understanding of the mechanism of carbonation and the factors affecting this progress haven't been established yet. The carbonation progress depends on the diffusivity of carbon dioxide in materials and the reactivity of materials to carbonation.

The diffusivity of carbon dioxide strongly depends on the transport properties of AAMs which have been introduced in the previous section. The parameters of carbonation conditions, especially relative humidity, also affect the process of diffusion. ${ }^{11}$ The effect of relative humidity on the progress of carbonation in AAMs was evaluated by Bernal et al. ${ }^{80}$, who observed that higher accelerated carbonation depths were observed at around $65 \%$ relative humidity, compared with the specimens at $80 \%$ and $50 \%$ relative humidity. Humidity determines the total amount of water present in the porous network of AAMs. When the pores are saturated with water for high humidity, it is difficult for gaseous carbon dioxide to diffuse, while the dry effects of low humidity would retard the dissolution of the carbon dioxide to form carbonic acid. ${ }^{81}$ Therefore, under intermediate humidity, the combination of superior reaction kinetics and higher rates of carbon dioxide diffusion accelerates the carbonation reaction process. ${ }^{82}$

Accelerated carbonation is always utilized to assess the carbonation resistance of AAMs. Under accelerated carbonation, many researchers observed that AAMs were more susceptible to carbonation compared with OPC-based material. ${ }^{83}$ But it was reported that the application of accelerated tests was not realistic to study the carbonation of AAMs

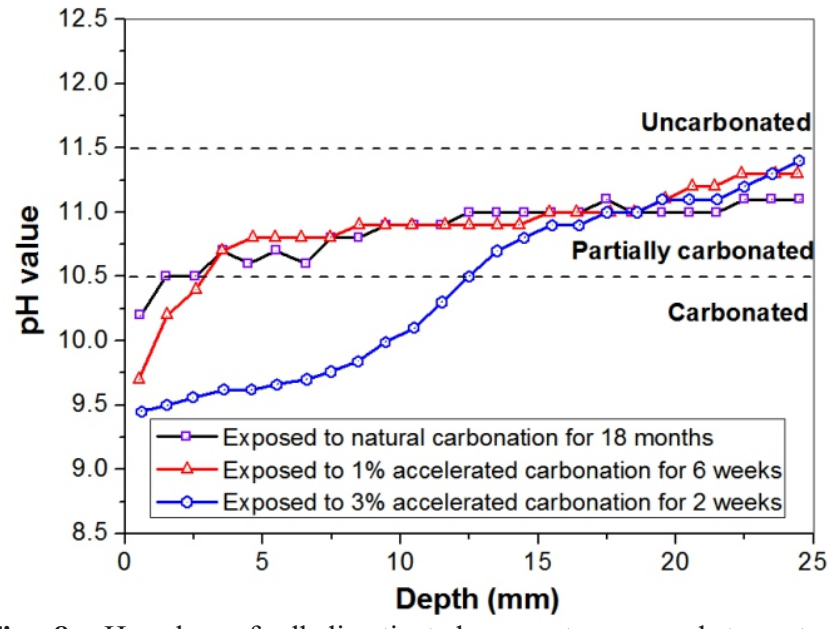

Fig. $8 \mathrm{pH}$ value of alkali-activated concrete exposed to natural carbonation for 18 months, $1 \%$ accelerated carbonation for 6 weeks, $3 \%$ accelerated carbonation for 2 weeks-adapted from Khan, et al. ${ }^{85}$

because it leads to not only an increase in the kinetics of reaction but also the difference of reaction products, in comparison with natural carbonation. ${ }^{84}$ Recently, based on the $\mathrm{pH}$ value of AAMs under natural carbonation and accelerated carbonation, as shown in Fig. 8, Khan et al. ${ }^{85}$ presented that $1.0 \%$ accelerate carbonation for 6 weeks could reproduce 18-month natural carbonation, with not only similar trend of $\mathrm{pH}$ value of carbonation but also the same carbonation product-natron. Based upon that, it was recommended that the carbon-dioxide content used in accelerated carbonation of AAMs should not be more than $1.0 \%$. However, further studies are required to validate this recommendation.

The nature of the activator and the composition of precursors have significant effects on the mechanism of carbonation through controlling the type of reaction products. As for the high-calcium system, Puertas et al. ${ }^{86}$ observed that carbonation was less intense in specimens activated by sodium hydroxide than in the specimens activated by sodium silicate. The differences in the composition and structure forming between these two systems could account for this phenomenon. In the case of the hydroxide-activated systems, the C-S-H exhibits a higher ratio of $\mathrm{Ca} / \mathrm{Si}$ than those activated by sodium silicate. The higher $\mathrm{Ca} / \mathrm{Si}$ ratio, along with the reduced silicate chain length observed in sodium hydroxide activated system, might favor the formation and precipitation of carbonate products to fill pore spaces, and this would influence the further diffusion of carbon dioxide within the materials. ${ }^{87}$ Nonetheless, different results were observed by Deja ${ }^{88}$, who reported that the carbonation depth of silicate-activated slag mortars was lower than that of hydroxide alkali-activated slag products. The results may be attributed to the denser microstructure of sodium silicate activated slag, compared with sodium hydroxide, and the more dense structure with the 
increased modulus of activator. ${ }^{83}$ Therefore, future studies are required to take all related factors such as the porosity and stability of gel as a whole when explaining the behaviors of AAMs under carbonation.

Concerning the low-calcium system, the N-A-S-H type gels appear to be unaltered under carbonation, and the carbonation of such material is mainly related to the conversion of pore solution ${ }^{89}$. The mechanism of natural carbonation in geopolymer material is hypothesized as carbonation of the sodium to form sodium carbonate, which causes only a small reduction in $\mathrm{pH}$ value. It was found that with the decreasing activator dosage, the fly ash based geopolymer mortars exhibit slightly lower final $\mathrm{pH}$ value after atmospheric carbonation. ${ }^{90}$ Badar et al. ${ }^{91}$ investigated the effect of calcium content on the performance of reinforced geopolymer concretes under accelerated carbonation. Three types of fly ash with different $\mathrm{Ca}$ content (from $2 \%, 5 \%$, to $13 \%$ ) were activated with a mixture of sodium silicate and sodium hydroxide. It was observed that the specimen prepared using fly ash with low calcium content exhibited a lower risk of corrosion of the steel rebar, not only owing to the lower carbonation depths but also the inconspicuous change in porosity. It was suggested that the fly ash with high $\mathrm{Ca}$ content promotes the formation of $\mathrm{C}-\mathrm{A}-\mathrm{S}-\mathrm{H}$ gel with lower $\mathrm{Ca} / \mathrm{Si}$ ratio and carbonation would cause the decalcification of the C-A-S-H type gel, resulting in a decrease of bonding in the matrix and following degradation of microstructure. ${ }^{92}$

\subsection{Alkali-aggregate reaction}

Alkali-aggregate reactions (AAR) are the processes that alkali hydroxide in pore solution reacts with reactive silica phase in aggregates, and then the alkali-silica gel formed causes expansion and cracking in concrete. Since activated by the solution with large amounts of alkalis, AAMs has the potential deterioration for AAR. Hence, factorial analyses are deserved to understand the resistance of AAMs to AAR. On the basis of the mechanism of AAR, it is believed that aggregate, raw materials and chemical activator are the three key factors that play essential roles in AAR of AAMs. ${ }^{93}$ Krivenko et al. ${ }^{94}$ studied the AAR of alkali-activated slag concretes using 5 different types of aggregate: 4 potentially alkalisusceptible aggregates (olivine, basalt, andesite, and perlite) and 1 type of quartz sand. The results showed that the degree of swelling was consistent with the alkali reactivity of aggregate, from high to low as the following: perlite, andesite, basalt, olivine, and quartz sand. Also, Tänzer et al. ${ }^{95}$ demonstrated that expansion of AAMs increased with the increased active aggregate content. Moreover, the size of aggregate has an effect on the reactivity of aggregate and correlatively the AAR induced expansions. Generally, the expansion degree dropped with the increase of the aggregate size, and the reduction of expansion with increasing aggregate size is more pronounced when the content of active aggregate is higher. ${ }^{96}$

Binder ingredients in AAMs also influence the degree of AAR expansion. There is a consensus that AAMs based on low-calcium precursors are less vulnerable to AAR, even with active aggregate. ${ }^{97,98}$ It was also reported that alkali-activated mortars based on fly ash and slag blend exhibited negligible AAR expansion with increasing content of fly ash. $^{99,} 100$ In alkali-activated fly ash based mortars, it was observed that crystalline zeolite products were formed in the pores instead of typical AAR gels found in alkali-activated slag, and the growth of zeolite would not cause the formation of cracks. Besides, the high fluidity of alkali-silica gel and the fast decrease of the $\mathrm{pH}$ value in pore solution have been proposed to explain the superior AAR resistance of AAMs based on low-calcium precursors, but these explanations still require further confirmation. ${ }^{101}$ Moreover, Chen et al. ${ }^{96}$ indicated that acid slag was beneficial to reduce the degree of destruction induced by AAR compared with the neutral or basic slag. The reduced degree of AAR is mainly due to that alkali hydroxide can be neutralized by the acid slag. But it simultaneously reduces the activity of alkali activation.

Generally, the binder matrix of AAMs becomes denser with increasing silica content. ${ }^{14}$ However, the increase in alkali-silicate gel viscosity and the rise in the water absorption, induced by increased silica content, would cause more significant expansion of alkali-silicate gel, and then results in an increased internal pressure in the matrix with low porosity. ${ }^{102}$ Tänzer et al. ${ }^{95}$ assessed the behaviors of slag-based alkali-activated mortars activated with alkali silicate solution at different alkali dosage and modulus. Typical findings are illustrated in Table 4, and it reveals that higher silica modulus at a constant alkali concentration resulted in a more obvious expansion. In another study, Chen et al. ${ }^{96}$ observed similar results. As shown in Fig. 9, mortar activated by water glass exhibits the highest expansion, and the lowest expansion rate is found in sodium hydroxide activated mortars when the

Table 4 Length changes of the alkali-activated slag mortar prisms activated with different activator after 224 days-adapted from Tänzer et al. ${ }^{95}$

\begin{tabular}{|c|c|c|c|c|}
\hline & $\mathrm{SiO}_{2} / \mathrm{M}_{2} \mathrm{O}(\mathrm{M}=\mathrm{Na}, \mathrm{K})$ & $\mathrm{n}_{\text {alkali }} / \mathrm{m}_{\text {solution }}(\mathrm{mol} / \mathrm{kg})$ & $\mathrm{n}_{\text {silica }} / \mathrm{m}_{\text {solution }}(\mathrm{mol} / \mathrm{kg})$ & Elongation $(\mathrm{mm} / \mathrm{m})$ \\
\hline Na-WG-0.5 (2) & 0.5 & 2.0 & 1.0 & 0.47 \\
\hline Na-WG-1.0 (2) & 1.0 & 2.0 & 2.0 & 0.49 \\
\hline Na-WG-2.0 (2) & 2.0 & 2.0 & 4.0 & 1.20 \\
\hline Na-WG-1.0 (4) & 1.0 & 4.0 & 4.0 & 0.46 \\
\hline K-WG-1.0 (2) & 1.0 & 2.0 & 2.0 & 1.08 \\
\hline K-WG-1.0 (4) & 1.0 & 4.0 & 4.0 & 0.15 \\
\hline K-WG-2.0 (2) & 2.0 & 2.0 & 4.0 & -0.48 \\
\hline K-WG-2.0 (4) & 2.0 & 4.0 & 8.0 & 0.75 \\
\hline
\end{tabular}




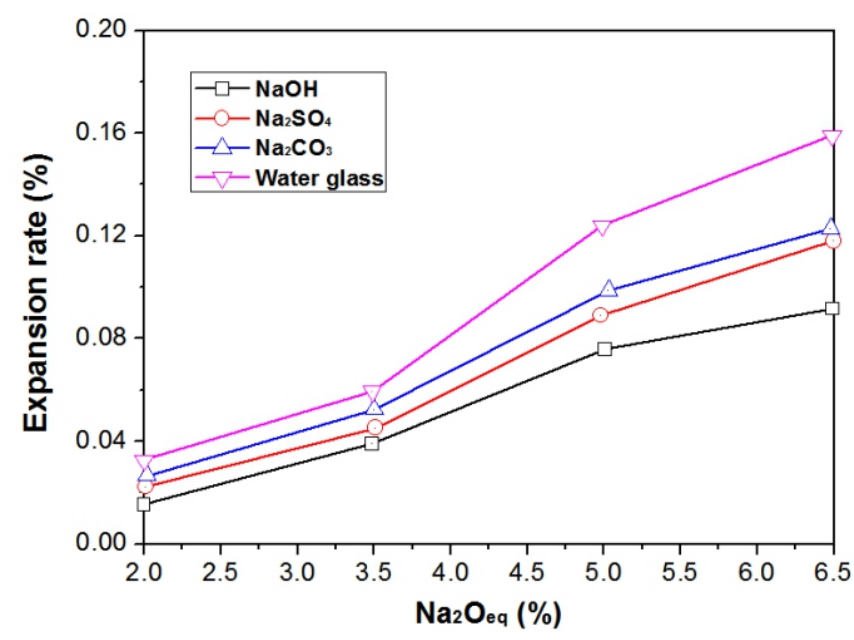

Fig. 9 Effect of types of activator and alkali content on AAR expansion of slag-based alkali-activated mortars-adapted from Chen, et al. ${ }^{96}$

content of alkali is constant.

Fig. 9 also illustrates that as the alkali content increases from 2.0 to $6.5 \%$, the expansion rates of specimens increase, in regardless the type of activators. ${ }^{96}$ While an opposite trend was detected in a recent study conducted by Shi et al. ${ }^{103}$, who showed that the AAR expansion of slag based mortars activated with sodium hydroxide decreased with increasing dosage of alkali, although the alkalinity of pore solution increased. It was explained that by increasing the content of alkali, the content of active alumina dissolved from the source materials increased, which had a beneficial effect in reducing expansion down to an allowable or even negligible level by controlling the alkali-silica gel structure formation process. ${ }^{94}$ Wang et al. ${ }^{104}$ also observed a similar phenomenon that an increase in alkali dosage involved a decline in AAR expansion, which was attributed to the significant improvement in the strength of materials. Obviously, the study of AAR in AAMs is not an overall subject, at least with regard to the effect of alkali content. Therefore, further studies are still needed to examine the influence of alkali content on the AAR resistance of AAMs. Shi et al. ${ }^{93}$ recommended that a combination of alkali content and silicate modulus should be investigated at the same time.

\section{Durability of AAMs based structures and products}

Most of the durability experiments to evaluate the durability of AAMs rely on accelerated testing but it should be pointed out that they sometimes cannot truly reflect the service conditions. For instance, the materials in structures during service life may suffer from multiple aging processes at the same time rather than a single process. Further, the load applied to the structure has effects on the durability characteristics or even greatly alter the deterioration kinetics. ${ }^{105}$ Hence, it is difficult to make a conclusion that the AAMs studied are able to provide reliable anti-corrosion properties in practical engineering even if their durability performances exhibited in the laboratory are superior. From this perspective, the in-site tests of long-term durability properties of structural elements based on AAMs is critical for the comprehensive knowledge of AAMs and the extension of commercial application. However, the research on the durability performance of AAMs during service life is really limited, let alone the study on the performance of structures using AAMs under aggressive environments. This section summarizes the published findings of research involving structures and products based on AAMs under aggressive environments, which includes beam, slab, box culvert, and protection coating or repair materials.

\subsection{Reinforced alkali-activated concrete beams}

Rakesh et al. ${ }^{106}$ examined the effect of carbonation on the lightly reinforced geopolymer beams. A blend of fly ash and slag activated with a combination of sodium silicate and hydroxide solution was mixed with aggregate to cast geopolymer beams $(100 \mathrm{~mm} \times 150 \mathrm{~mm} \times 1000$ $\mathrm{mm})$. After curing for 28 days at room temperature, they were exposed to accelerate carbonation for a period of 48, 96 and 144 hours. During the experiment, the depth of carbonation and ultimate loads under flexural test were compared with control specimens without carbonation. It was found that the ultimate load and depth of carbonation increased with the increase of the duration of carbonation. However, due to the relatively short period of carbonation, the difference in carbonation depth was marginal, and the carbonation depth was smaller than the thickness of concrete cover to reinforcement.

Bayuaji et al. ${ }^{107}$ investigated the effects of the marine environment on the flexural strength of reinforced fly ash-based geopolymer concrete beams $(100 \times 150 \times 1500 \mathrm{~mm})$. After cured in the seawater at the seashore for 28 days, the geopolymer concrete beams were loaded by flexural load under four-point bending test and then test results were compared with those of the geopolymer concrete beams cured at room temperature as shown in Fig. 10. It was observed that the ultimate loads and the crack patterns of specimens cured in seawater and room temperature were very similar, but the cracking load of the beams curing in seawater was higher than that of beams curing in room temperature. Similarly, Reddy et al. ${ }^{108}$ reported that the flexural strength of geopolymer concrete beams $(150 \times 150 \times 525 \mathrm{~mm})$ after accelerated corrosion test in natural seawater was higher than that of ordinary concrete beams, up to $240 \%$. However, Yodsudjai ${ }^{109}$ found that under $\mathrm{NaCl}$ solution, the corrosion of the steel reinforcement was more serious and the loss of flexural strength was higher in fly ash-based geopolymer reinforced concrete beams, compared with that of the conventional reinforced concrete beams.

The flexural behavior of geopolymer reinforced concrete beams $(100 \mathrm{~mm} \times 100 \mathrm{~mm} \times 500 \mathrm{~mm})$ after exposed to acids and sulfates for 180 days were studied by Kannapiran et al. ${ }^{110}$. Limited reduction (less than $8 \%$ ) in the flexural strength and no significant changes to the loaddeflection relationship were found in the specimens even after immersed in the sulfuric acid solution or the combination of hydrochloric and sulfuric acid solutions. In addition, the effect of sulfate corrosion on reinforced geopolymer concrete beams was insignificant in terms of strength or appearance.

Mathew and Joseph ${ }^{111}$ studied the flexural behaviors of fly ash based geopolymer concrete beams $(150 \times 200 \times 1100 \mathrm{~mm})$ cast with $0.52 \%$ reinforcing steel, after exposure to elevated temperatures $(200$ ${ }^{\circ} \mathrm{C}, 400{ }^{\circ} \mathrm{C}, 600{ }^{\circ} \mathrm{C}$ and $800{ }^{\circ} \mathrm{C}$ ). The deformation characteristics, moment-curvature relationship, and cracking behavior were observed during the test. It could be concluded that the deformation characteristics of reinforced geopolymer concrete beams at ambient temperature were similar to those of the reinforced conventional concrete beams and could be predicted using strain compatibility approach. However, when they were exposed to elevated temperatures, the strain compatibility approach underestimated the deformation behaviors of reinforced geopolymer concrete beams. Further, the ductility of the geopolymer concrete beams was reduced rapidly with the increase of exposure temperature.

\subsection{Reinforced alkali-activated concrete slabs}




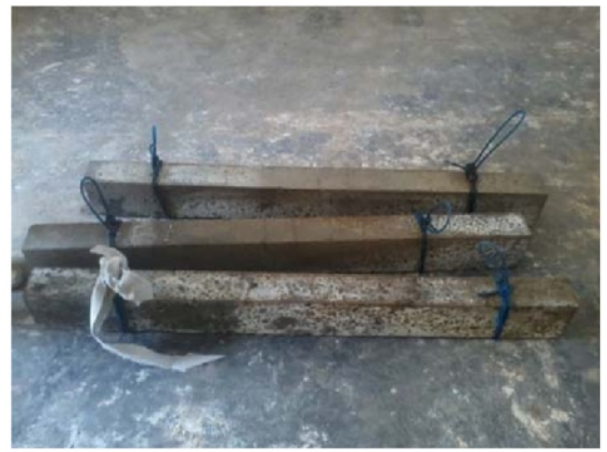

(a) Geopolymer concrete beam cured in seawater

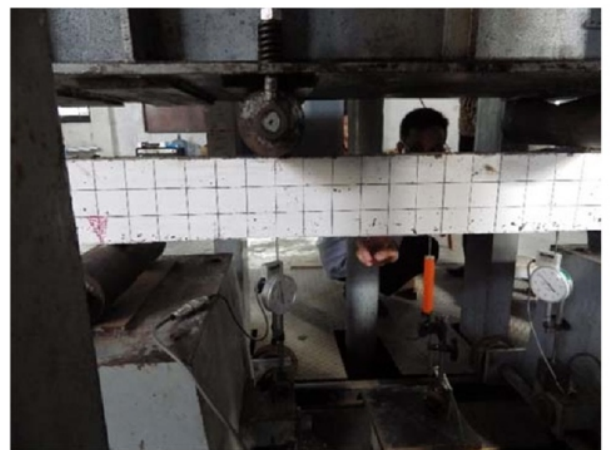

(b) Loading test arrangement

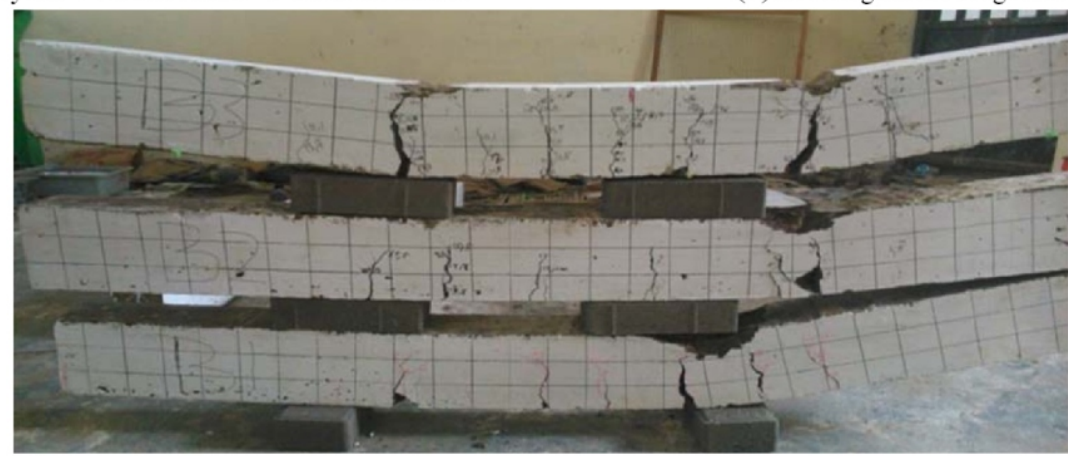

(c) Crack pattern of beams cured in seawater

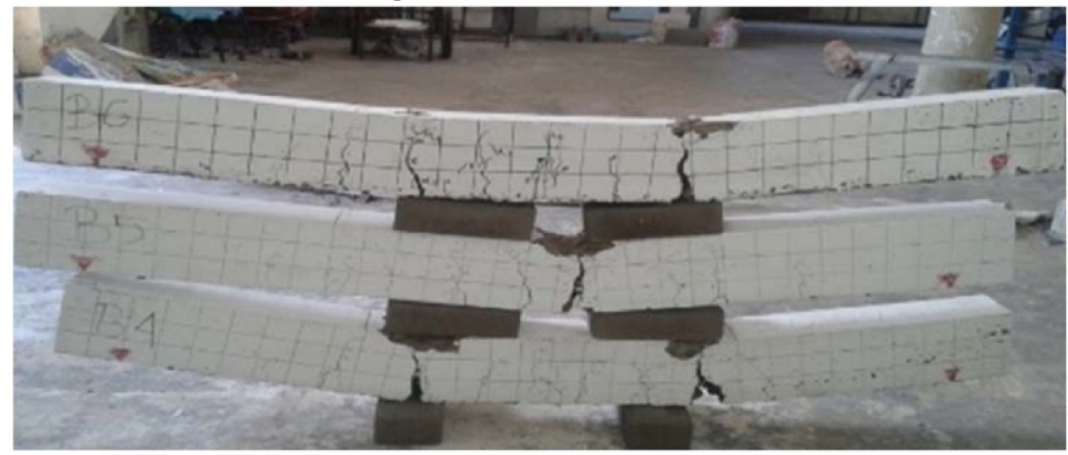

(d) Crack pattern of beams cured in room temperature

Fig. 10 Flexural test of fly ash-based geopolymer concrete beams cured in seawater and room temperature-adapted from Bayuaji, et al. ${ }^{107}$

Pasupathy et al. ${ }^{112}$ investigated the degrees of carbonation in two adjacent reinforced blended fly ash/slag geopolymer concrete slabs after 8-year exposure to atmospheric carbonation. Different mix compositions of geopolymer concrete were used for casting these two types of slab: a combination of $25 \%$ slag and $75 \%$ fly ash activated by a mixture of potassium and sodium hydroxide, and additional sodium silicate was used for Type 1 slab, while 30\% slag and $70 \%$ fly ash with only a mixture of potassium and sodium hydroxide as activator was used for Type 2 slab. As shown in Fig. 11, core specimens were taken from the slab and sprayed with phenolphthalein indicator to measure the carbonation depth. Compared with test results of Portland concrete in the literature, Type 1 geopolymer concrete exhibited similar resistance to carbonation, with carbonation depth of 8-14 mm, whereas, Type 2 geopolymer concrete showed poor resistance to carbonation with carbonation depth of 23.5-27.5 mm. Besides, the lower total porosity and sorptivity were found in Type 2 geopolymer concrete.

Li et al. ${ }^{113}$ studied the effects of exposure duration and temperatures on the mechanical performance of alkali-activated slag concrete panels. The steel fiber reinforced alkali-activated slag concrete was used to prepare the panel specimens $(350 \times 100 \times 40 \mathrm{~mm})$ with basalt textile reinforcements. Three-point bending tests were conducted to study the flexural behaviors of the specimens after heated to $400{ }^{\circ} \mathrm{C}, 600{ }^{\circ} \mathrm{C}$, and $800{ }^{\circ} \mathrm{C}$ for durations of 1.0 and 2.0 hours. Fig. 12 presents the loaddisplacement curves of specimens exposed and not exposed to high temperature. The first crack strength and peak flexural strength of the specimens without exposure to heat reached 8.9 MPa and 20.5 MPa, respectively. Even though obvious decreases in flexural performance occurred with the increase in temperature or duration as a result of the decomposition of the alkali-activated slag mortar matrix and the deterioration of the bonding between the basalt textile and the matrix, the peak flexural strengths of the specimens that suffered 1 and 2 hours of heat treatment at $800{ }^{\circ} \mathrm{C}$ still reached $2.1 \mathrm{MPa}$ and $1.7 \mathrm{MPa}$, respectively.

Sarker and Mcbeath ${ }^{114}$ studied the damages and residual strength of reinforced fly ash geopolymer concrete panels after 2-hour fire exposure, and compared the behavior of geopolymer panels with that of normal concrete panels. The panel specimens were $500 \times 500 \mathrm{~mm}$ in size and $125 \mathrm{~mm}, 150 \mathrm{~mm}$ and $175 \mathrm{~mm}$ in thickness. Under high temperature (up to $1000{ }^{\circ} \mathrm{C}$ ), lower temperature differential was detected in the geopolymer concrete panels than in the OPC concrete panels with 


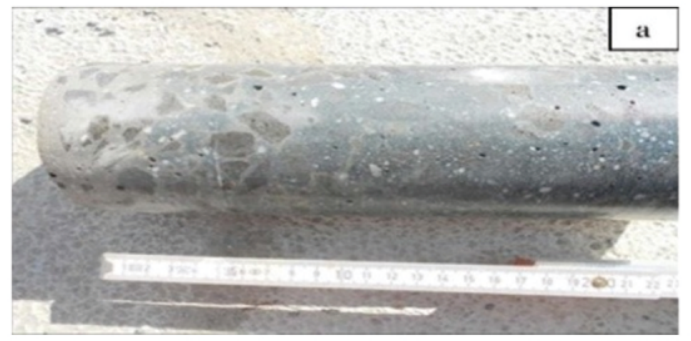

(a) Type 1 specimens before measurements

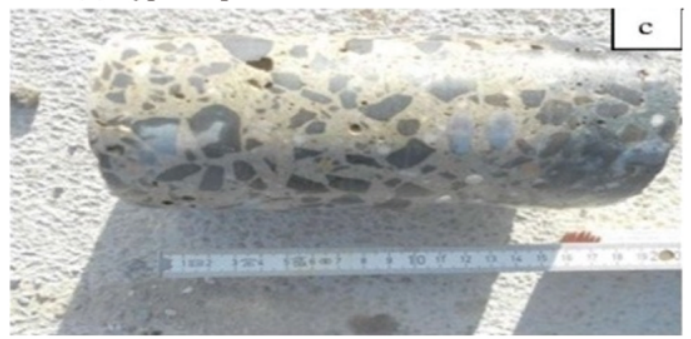

(c) Type 2 specimens before measurements

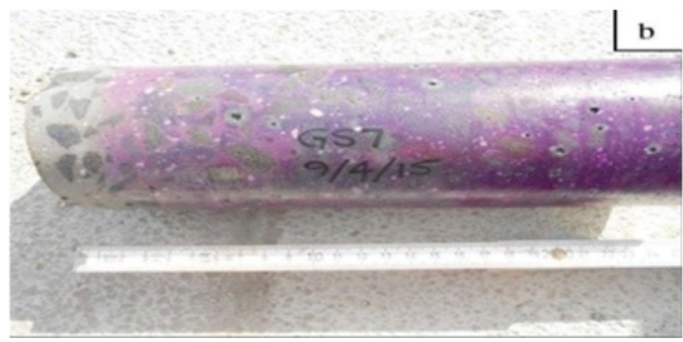

(b) Type 1 specimens after applying phenolphthalein

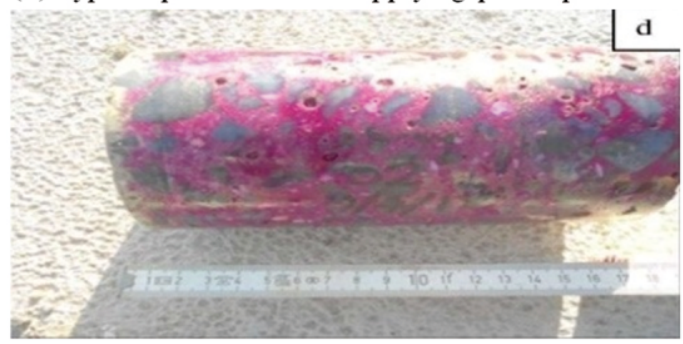

(d) Type 2 specimens after applying phenolphthalein

Fig. 11 Carbonation depth measurements of specimens-adapted from Pasupathy, et al. ${ }^{112}$
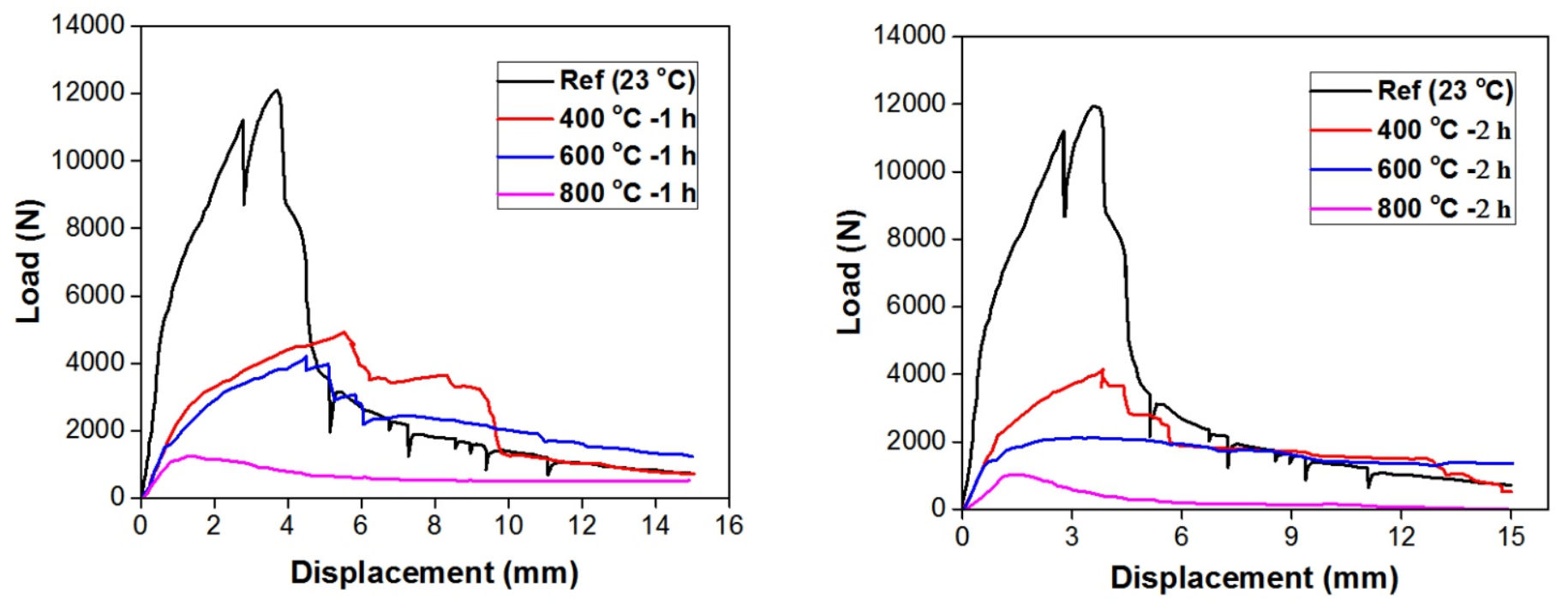

Fig 12 Load-displacement curves of panel specimens exposed/not exposted to heat-adapted from Li, et al. ${ }^{113}$

the same thickness, which was due to the faster heat transformation in the geopolymer concrete panels. Also, geopolymer concrete panels exhibited fewer damages by cracking and spalling. After cooling down to room temperature, the panel specimens were loaded to failure to study the post-fire strength. The geopolymer concrete panels demonstrated less strength loss than the OPC concrete panels. Specifically, the mean value of the percentage strength loss of the geopolymer panels and OPC concrete panels was $34 \%$ and $48 \%$, respectively. All these showed that the steel reinforced fly ash geopolymer concrete slab possessed superior fire resistance in comparison with OPC concrete elements.

\subsection{Reinforced alkali-activated concrete box culvert}

Pasupathy et $a l .{ }^{115}$ investigated the durability of box culverts using geopolymer and OPC concrete, after 6-year exposure to a saline lake environment. Fly ash with low content of calcium was activated by sodium hydroxide and silicate solution to prepare the geopolymer binder. Core specimens were extracted from the leg and top slab of the culverts and were assessed in terms of the depth of carbonation, sulfate attack, chloride penetration, microstructure, and porosity as shown in Fig. 13. Although the geopolymer concrete had smaller average pore sizes, its porosity was slightly higher, and it was more susceptible to carbonation and chloride penetration compared with OPC concrete. For instance, complete carbonation and chloride penetration were found in the core specimens from leg slab of the geopolymer concrete culver as opposed to only $10 \mathrm{~mm}$ and $20 \mathrm{~mm}$, respectively, for the depth of carbonation and chloride penetration in that of the OPC concrete culvert. Consequently, corrosion products were observed at the steel/concrete interface in the geopolymer concrete, whereas they were invisible in OPC concrete.

\subsection{AAMs for coating or repairing}




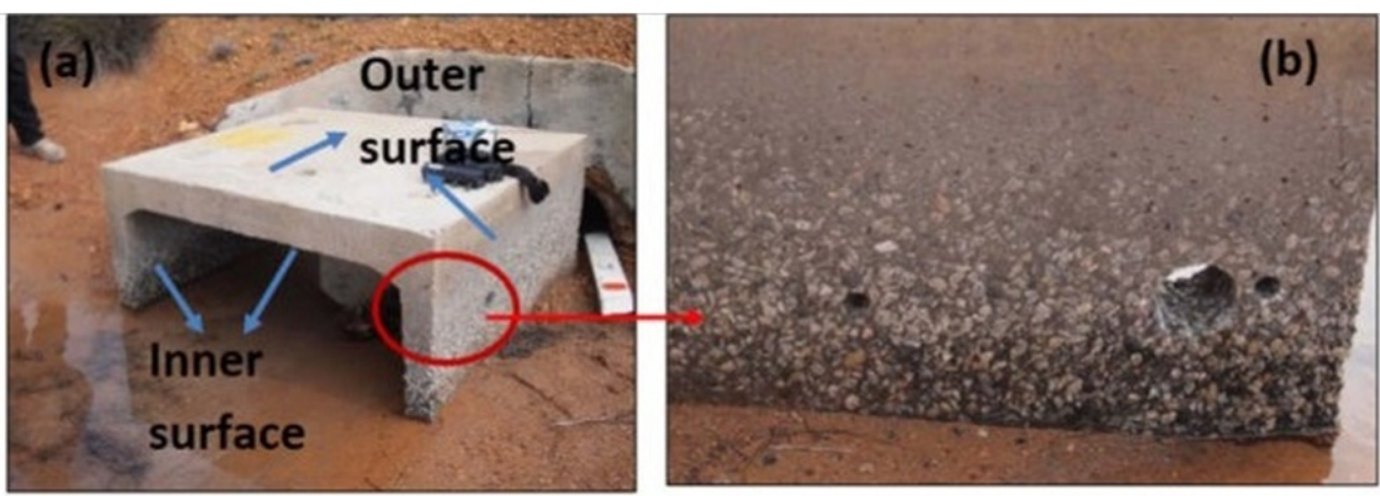

(a) Geopolymer concrete culvert; (b) exposed aggregate on the outer surface of geopolymer concrete
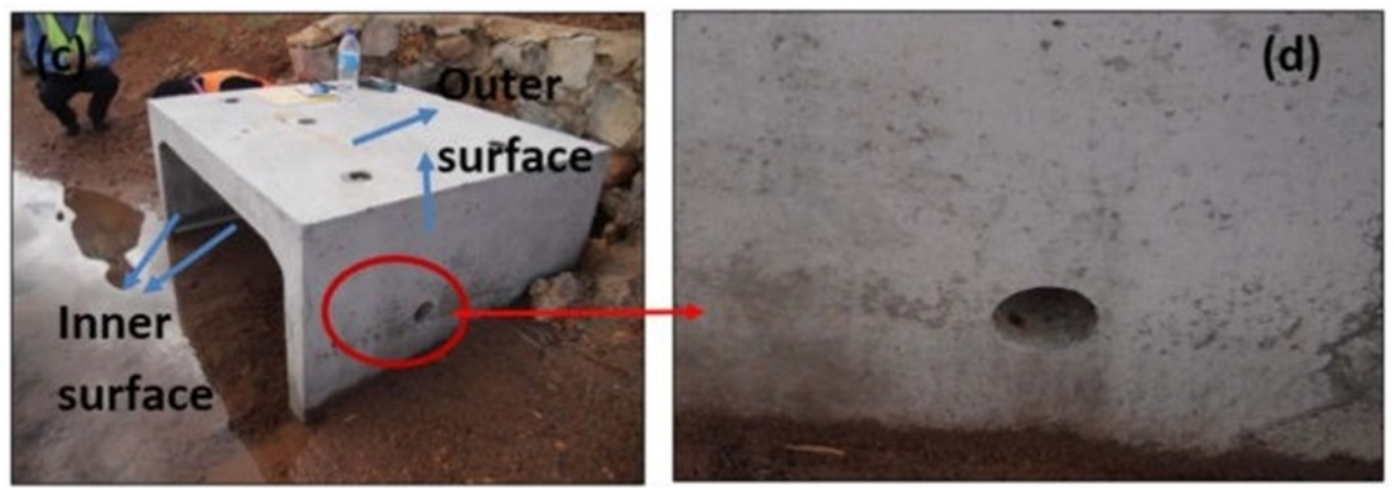

(c) OPC concrete culvert; (d) the outer surface of OPC without visual deterioration

Fig. 13 The visual appearance of concrete box culverts-adapted from Pasupathy, et al. ${ }^{115}$

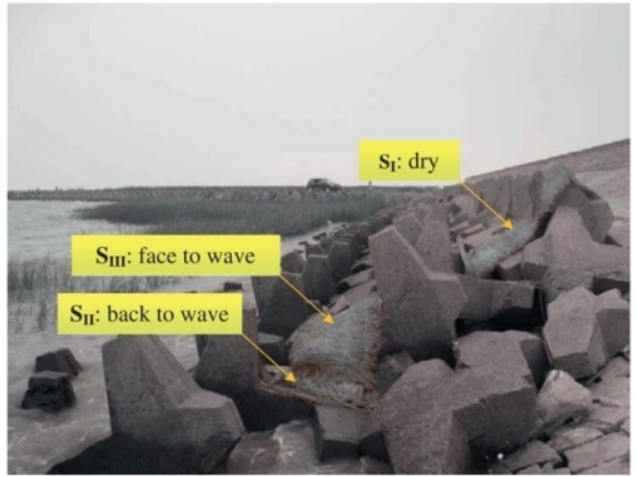

(a) The surfaces of three concrete accropodes to be coated

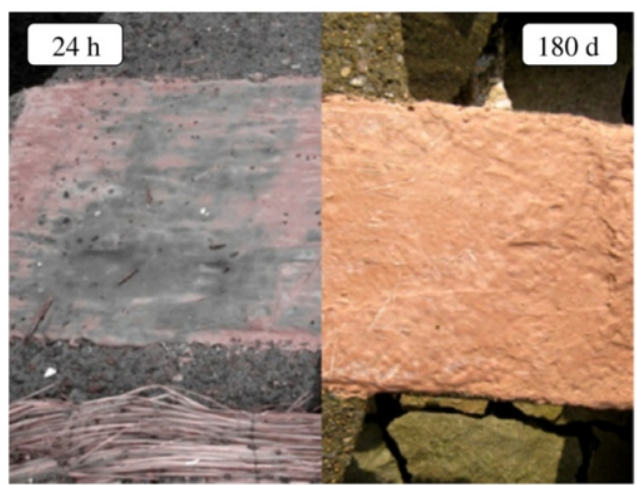

(c) Geopolymer coatings solidified for 24 hour and cured for 180 days

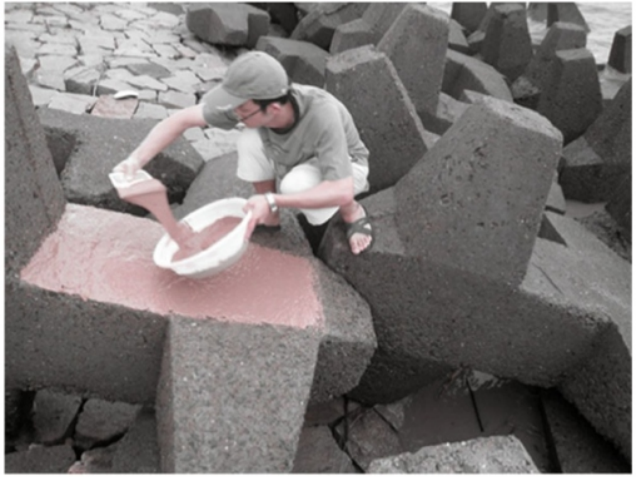

(b) Application of geopolymer coatings to concrete accropodes

Fig. 14 Field experiment of AAMs as protection coatings for marine concrete-adapted from Provis and Deventer ${ }^{71}$ Zhang, et al. ${ }^{116}$ 
Zhang et al. ${ }^{19,20,116}$ conducted a series of experiments to investigate the potential of geopolymers as an endurable anticorrosion coating to protect concrete under marine environments. Based on the experimental investigation into basic properties, including solidifying time, water permeability, shrinkage, bond strength, and corrosion resistance, as well as microstructure and anticorrosion mechanism of geopolymers, it was found that geopolymer pastes based on alkali-activated fiber-reinforced slag/metakaolin had the potential of being used in the protective coating. ${ }^{19}{ }^{20}$ Such material was applied on-site to concrete accropodes' surfaces at a coast site with a thickness of $3 \mathrm{~mm}$ or $5 \mathrm{~mm}$ as shown in Fig. 14. It was found that this coating exhibited suitable setting time and higher bonding strength under the field condition. In addition, a limited amount of calcite was detected by XRD, and no sulfate was found even after exposure to the marine environment for 6 months, demonstrating excellent chemical stability. Although the high-speed wind resulted in shrinkage cracks on the coating, increasing thickness, curing humidity, and incorporating suitable aggregates could solve this problem. ${ }^{116}$ Therefore, these results showed that geopolymer could be used as an ideal coating material with low permeability and high resistance to marine corrosion.

The properties of geopolymer mortars as repair materials have been studied by Yodsudjai ${ }^{109}$, who developed a repair mortar based on fly ash-based geopolymer to repaired corroded reinforced concrete beams. The experimental results exhibited that the properties of the fly ash-based geopolymer mortar were closed to that of commercial repair materials, and the durability of the reinforced concrete beam repaired by the fly ash-based geopolymer mortars performed slightly lower than that repaired with commercial repair mortar. As a result, although there is still a need for improvement in properties, it is a good tendency for using the fly ash-based geopolymer as the repair material for structural members.

Varela and Privorotskaya ${ }^{117}$ investigated the ability of metakaolin based geopolymer as coatings to protect concrete substrates from deteriorating under high temperature. Two different geopolymer coatings with a thickness of $6 \mathrm{~mm}$, one based on metakaolin and the other based on metakaolin with amorphous silica, were applied to mortar cubes respectively. Mortar cubes were heated in a furnace at 450 ${ }^{\circ} \mathrm{C}$ and $800{ }^{\circ} \mathrm{C}$ for one hour, and then mortar cubes were tested for compressive strength. Experimental results showed that the geopolymer coatings offered outstanding protection to concrete substrates. For instance, at the temperature of $800{ }^{\circ} \mathrm{C}$, uncoated specimens experienced disintegration while the coated specimens maintain their integrity and retained a high percentage of compressive strength. Similar results were also observed by Sakkas et al. ${ }^{118}$, who sustained that alkali-activated slag material could effectively act as a flame and heat barrier. In addition to being used on concrete substrates, AAMs have also been applied to coat on metal substrates. Temuujin et al. ${ }^{119}$ developed and tested fly ash-based geopolymers as fire resistant coatings on steel element. The heat insulating characteristics of the coatings were evaluated by measuring the time necessary for the unexposed side to reach a temperature of $180{ }^{\circ} \mathrm{C}$ above the ambient temperature. The experimental results showed that the adhesive strength of the coating to steel could be higher than $3.5 \mathrm{MPa}$, with a measured insulating capacity of 9 minutes. In another study, metakaolin-based geopolymers also exhibited the potential of using as fire resistance coatings on steel substrates. $^{120}$

\section{Conclusions}

With growing environmental consciousness, AAMs have taken the spotlight for such material reduces greenhouse gas emissions, contributes to sustainable development and helps solid waste management. In order to achieve a high degree of sustainability, AAMs must also have high durability to reduce the maintenance costs and extend the service life. This study presented a critical review of the durability performance of AAMs from the material to structure. Several conclusions have been drawn, providing a reference for the research community and the AAMs industries to promote more sustainable use of this green material.

(1) AAMs have the potential to become a durable material by appropriate selection of source materials, adjustment in chemical activators, and optimization of mixing design. Determining the optimum mixture for industrial by-products from different locations can facilitate the application of AAMs, which is also likely to solve industry waste management issues in those areas or regions.

(2) The kinetics and severity of deterioration in AAMs are closely connected to the parameters of external environments, for instance, the concentration of carbon dioxide, cation accompanying sulfate and type of acid. When designing AAMs for a specific environment, all possible deterioration processes should be considered to achieve high performance and low maintenance during the service life.

(3) Several methods can improve the durability of AAMs by ameliorating the chemical stability or physical permeability, such as utilizing finer source materials, applying heat treatment or other types of curing regime, and incorporating nano-materials.

(4) The service conditions of AAMs, including the mechanical loads and environmental actions, can alter the deterioration kinetics. Further, as multiple aging processes occur simultaneously, the durability performance of AAMs under service conditions is different from that under a single process.

\section{Perspectives}

Although the research on the durability of AAMs has been rapidly growing, there are still significant gaps in a comprehensive understanding of their corrosion mechanism and broad applications. Hence, further research is needed:

(1) Delicate studies, especially those related to the reaction kinetics under various aggressive environments, are required to develop complete elucidation and modeling. They could serve as a general guideline for researchers or designers in identifying the crucial factors and parameters to be considered for AAMs design and fabrication.

(2) AAMs and OPC systems require extensive comparative studies to examine the feasibility of current specifications to AAMs. In the meantime, developing a new standard methodology to assess durability performance of AAMs is urgently needed. It not only provides reliable durability testing data, but also facilitates researchers to compare the experimental results under comparable environmental conditions, and further give an insight into the corrosion mechanism.

(3) The necessity of examining the durability of materials and structures based on AAMs in suit is evident. Furthermore, it is important to establish better communication between the materials design and the structural design, so that structures based on AAMs could be better designed with the improved chemical formulation.

(4) The environmental and social credentials and performance of AAMs call for the overall examination based on the life cycled assessment in which the durability and service life of materials should be considered. Besides, the collection of the relevant data at 
the local scale by accessing the producers, as well as at the national and regional scale is an urgent step.

\section{Conflict of interest}

There are no conflicts to declare.

\section{Acknowledgment}

The authors gratefully acknowledge the support from the Australian Research Council (De150101751), Australia, and Australian Research Council (ARC) Industrial Transmission Research Hub "Nanogeopolymer composites for underground prefabricated structures" with Wuhan Zhihe Geotechnical Engineering Co., Ltd (IH150100006). The authors are also grateful for the financial support of State Key Laboratory of Subtropical Building Science (South China University of Technology), China (2019ZA06), the National Engineering Laboratory for High-speed Railway Construction (Central South University), China (HSR2017001) and the State Key Laboratory of Silicate Materials for Architectures (Wuhan University of Technology), China (SYSJJ2018$01)$.

\section{References}

1. J. A. Ober, Mineral commodity summaries 2018, US Geological Survey, 2018.

2. E. Gartner, Cem. Concr. Res., 2004, 34, 1489-1498.

3. R. Kajaste and M. Hurme, J. Cleaner Prod., 2016, 112, 4041-4052.

4. M. S. Imbabi, C. Carrigan and S. McKenna, Int. J. Sustainable Built Environ., 2012, 1, 194-216.

5. J. L. Provis and J. S. J. Van Deventer, Geopolymers: structures, processing, properties and industrial applications, Elsevier, 2009.

6. Z. Tang, W. G. Li, Y. Hu, J. Zhou and V. Tam, Constr. Build. Mater., 2019, 200, 474-489.

7. X. Y. Zhuang, L. Chen, S. Komarneni, C. H. Zhou, D. S. Tong, H. M. Yang, W. H. Yu and H. Wang, J. Cleaner Prod., 2016, 125, 253-267.

8. V. Nikolic, M. Komljenovic, N. Dzunuzovic and Z. Miladinovic, $J$ Hazard Mater, 2018, 350, 98-107.

9. S. A. Bernal and J. L. Provis, J. Am. Ceram. Soc., 2014, 97, 997-1008.

10. W. K. Part, M. Ramli and C. B. Cheah, Constr. Build. Mater, 2015, 77, 370395.

11. J. L. Provis, A. Palomo and C. Shi, Cem. Concr. Res., 2015, 78, 110-125.

12. I. Ismail, S. A. Bernal, J. L. Provis, R. San Nicolas, D. G. Brice, A. R. Kilcullen, S. Hamdan and J. S. van Deventer, Constr. Build. Mater, 2013, 48, 1187-1201.

13. M. Ben Haha, G. Le Saout, F. Winnefeld and B. Lothenbach, Cem. Concr. Res., 2011, 41, 301-310.

14. D. Ravikumar and N. Neithalath, Cem. Concr. Compos., 2012, 34, 809-818.

15. Q. Wang, J. Da, C. B. Zhang, Z. Y. Ding and Z. T. Sui, Advanced Materials Research, 2012, 450, 428-432.

16. A. Fernández-Jiménez and A. Palomo, Cem. Concr. Res., 2005, 35, $1984-$ 1992.

17. B. Singh, M. Rahman, R. Paswan and S. Bhattacharyya, Constr. Build. Mater, 2016, 118, 171-179.

18. H. Zhu, Z. Zhang, Y. Zhu and L. Tian, Constr. Build. Mater., 2014, 65, 5159.

19. Z. Zhang, X. Yao and H. Zhu, Appl. Clay Sci., 2010, 49, 1-6.

20. Z. Zhang, X. Yao and H. Zhu, Appl. Clay Sci., 2010, 49, 7-12.

21. J. L. Provis, R. J. Myers, C. E. White, V. Rose and J. S. van Deventer, Cem. Concr. Res., 2012, 42, 855-864.

22. S. Kumar, R. Kumar and S. Mehrotra, J. Mater. Sci., 2010, 45, 607-615.

23. P. D. Silva, K. Sagoe-Crenstil and V. Sirivivatnanon, Cem. Concr. Res., 2007, 37, 512-518.

24. P. Chindaprasirt and W. Chalee, Constr. Build. Mater, 2014, 63, 303-310.

25. C. Chotetanorm, P. Chindaprasirt, V. Sata, S. Rukzon and A. Sathonsaowaphak, J. Mater. Civ. Eng., 2012, 25, 105-111.

26. C. Gunasekara, D. W. Law and S. Setunge, Constr. Build. Mater, 2016, 124, 352-362.
27. A. Sathonsaowaphak, P. Chindaprasirt and K. Pimraksa, J Hazard Mater, 2009, 168, 44-50.

28. P. Chindaprasirt, U. Rattanasak and S. Taebuanhuad, Adv. Powder Technol., 2013, 24, 703-707.

29. J. Temuujin, A. Minjigmaa, M. Lee, N. Chen-Tan and A. Van Riessen, Cem. Concr. Compos., 2011, 33, 1086-1091.

30. P. Chindaprasirt, U. Rattanasak and S. Taebuanhuad, Mater. Struct., 2013, 46, 375-381.

31. S. Aydın and B. Baradan, Materials \& Design, 2012, 35, 374-383.

32. P. Hou, R. Li, Q. Li, N. Lu, K. Wang, M. Liu, X. Cheng and S. Shah, ES Materials \& Manufacturing, 2018, 1, 57-66.

33. T. Phoo-ngernkham, P. Chindaprasirt, V. Sata, S. Hanjitsuwan and S. Hatanaka, Materials \& Design, 2014, 55, 58-65.

34. A. Nazari and J. G. Sanjayan, Measurement, 2015, 60, 240-246.

35. P. Duan, C. Yan, W. Luo and W. Zhou, Constr. Build. Mater, 2016, 106, 115-125.

36. M. Morsy, S. Alsayed and M. Aqel, Constr. Build. Mater, 2011, 25, 145 149.

37. H. Khater and H. A. El Gawaad, Constr. Build. Mater, 2016, 102, 329-337.

38. Y. Fu, L. Cai and W. Yonggen, Constr. Build. Mater., 2011, 25, 3144-3148.

39. F. Shahrajabian and K. Behfarnia, Constr. Build. Mater, 2018, 176, 172-178.

40. L. Cai, H. Wang and Y. Fu, Constr. Build. Mater., 2013, 49, 70-76.

41. J. Shi, PhD Thesis, Louisiana Tech University Ruston, LA, 2012.

42. S. Pilehvar, A. M. Szczotok, J. F. Rodríguez, L. Valentini, M. Lanzón, R. Pamies and A.-L. Kjøniksen, Constr. Build. Mater, 2019, 200, 94-103.

43. H. Rostami and W. Brendley, Environ. Sci. Technol., 2003, 37, 3454-3457.

44. N. Lee, K. Koh, G. An and G. Ryu, Ceram. Int., 2017, 43, 2471-2480.

45. W. Wang, H. Wang and M. Lo, Constr. Build. Mater, 2014, 68, 409-415.

46. O. Karahan and A. Yakupoğlu, Adv. Cem. Res., 2011, 23, 289-297.

47. T. Bakharev, Cem. Concr. Res., 2006, 36, 1134-1147.

48. D. Panias, E. Balomenos and K. Sakkas, in Handbook of Alkali-activated Cements, Mortars and Concretes, Elsevier, 2015, pp. 423-461.

49. M. Guerrieri and J. G. Sanjayan, Fire Mater, 2010, 34, 163-175.

50. Z. Pan, Z. Tao, Y. F. Cao, R. Wuhrer and T. Murphy, Cem. Concr. Compos., 2017.

51. D. L. Kong, J. G. Sanjayan and K. Sagoe-Crentsil, Cem. Concr. Res., 2007, 37, 1583-1589.

52. W. D. Rickard, J. Temuujin and A. van Riessen, J. Non-Cryst. Solids, 2012, 358, 1830-1839.

53. D. L. Kong, J. G. Sanjayan and K. Sagoe-Crentsil, J. Mater. Sci., 2008, 43, 824-831.

54. D. L. Kong and J. G. Sanjayan, Cem. Concr. Res., 2010, 40, 334-339.

55. H. Zhang, V. Kodur, S. Qi, L. Cao and B. Wu, Constr. Build. Mater, 2014, 55, 38-45.

56. P. Rovnaník and A. Dufka, Mater. Tech, 2015, 49, 709-713.

57. A. M. Rashad, Proceedings of the Institution of Civil EngineersConstruction Materials, 2017, 1-8.

58. D. L. Y. Kong and J. G. Sanjayan, Cem. Concr. Res., 2010, 40, 334-339.

59. C. Shi, D. Roy and P. Krivenko, Alkali-activated cements and concretes, CRC press, 2006

60. F. Pacheco-Torgal, Z. Abdollahnejad, A. Camões, M. Jamshidi and Y. Ding, Constr. Build. Mater., 2012, 30, 400-405.

61. T. Bakharev, Cem. Concr. Res., 2005, 35, 658-670.

62. C. Shi and J. Stegemann, Cem. Concr. Res., 2000, 30, 803-808.

63. T. Sugama, L. Brothers and T. Van de Putte, Adv. Cem. Res., 2005, 17, 6575.

64. N. Lee and H. Lee, Cem. Concr. Compos., 2016, 72, 168-179.

65. A. Buchwald, K. Dombrowski and M. Weil, in Poceedings of the World Congress Geopolymer, ed. J. Davidovits, Saint Quentin, France, 2005, pp. 35-39.

66. K. Bouguermouh, N. Bouzidi, L. Mahtout, L. Pérez-Villarejo and M. L. Martínez-Cartas, J. Non-Cryst. Solids, 2017, 463, 128-137.

67. A. Allahverdi and F. Skvara, Ceramics Silikaty, 2005, 49, 225.

68. R. R. Lloyd, J. L. Provis and J. S. van Deventer, Mater. Struct., 2012, 45, 114.

69. W. Jiang, M. Silsbee, E. Breval and D. Roy, in Mechanisms of Chemical Degradation of Cement-Based Systems, ed. Y. JF, E \& FN Spon, London, 1997, pp. 289-296. 
70. P.-T. Fernando, C.-G. João and J. Said, J. Mater. Civ. Eng., 2010, 22, 897 904.

71. J. L. Provis and J. S. J. V. Deventer, Alkali Activated Materials, Springer Netherlands, 2014

72. S. A. Bernal, E. D. Rodríguez, R. Mejía de Gutiérrez and J. L. Provis, Journal of Sustainable Cement-Based Materials, 2012, 1, 138-151.

73. M. D. Cohen and B. Mather, Materials Journal, 1991, 88, 62-69.

74. T. Bakharev, Cem. Concr. Res., 2005, 35, 1233-1246.

75. M. B. Karakoç, İ. Türkmen, M. M. Maraş, F. Kantarci and R. Demirboğa, Ceram. Int., 2016, 42, 1254-1260.

76. Ismail, S. A. Bernal, J. L. Provis, S. Hamdan and J. S. van Deventer, Mater. Struct., 2013, 46, 361-373.

77. W. G. Valencia Saavedra, D. E. Angulo and R. Mejía de Gutiérrez, J. Mater Civ. Eng., 2016, 28, 04016148

78. S. A. Hasanein, H. M. Khate, S. A. El-Enein and H. El-Sayed, CeramicsSilikáty, 2011, 55, 153-160.

79. F. Puertas, R. Gutierrez, A. Fernández-Jiménez, S. Delvasto and J. Maldonado, Materiales de Construccion, 2002, 52, 55-71.

80. S. A. Bernal, J. L. Provis, R. M. De Gutiérrez and J. S. van Deventer, Mater Struct, 2015, 48, 653-669.

81. Y. F. Houst and F. H. Wittmann, Cem. Concr. Res., 1994, 24, 1165-1176.

82. S. A. Bernal, in Handbook of Alkali-Activated Cements, Mortars and Concretes, Elsevier, 2015, pp. 319-332.

83. S. A. Bernal, R. M. De Gutierrez, J. L. Provis and V. Rose, Cem. Concr. Res., 2010, 40, 898-907.

84. S. A. Bernal, J. L. Provis, D. G. Brice, A. Kilcullen, P. Duxson and J. S. van Deventer, Cem. Concr. Res., 2012, 42, 1317-1326.

85. M. S. H. Khan, A. Castel and A. Noushini, Mag. Concr. Res., 2016, 69, 111.

86. F. Puertas, M. Palacios and T. Vázquez, J. Mater. Sci., 2005, 41, 3071-3082.

87. M. Palacios and F. Puertas, J. Am. Ceram. Soc., 2006, 89, 3211-3221.

88. J. Deja, Silic. Indus., 2002, 37-42.

89. M. Criado, A. Palomo and A. Fernández-Jiménez, Fuel, 2005, 84, 20482054.

90. Q. Wang, J. Da, C. B. Zhang, Z. Y. Ding and Z. T. Sui, Applied Mechanics and Materials, 2012, 152, 536-541.

91. M. S. Badar, K. Kupwade-Patil, S. A. Bernal, J. L. Provis and E. N. Allouche, Constr. Build. Mater, 2014, 61, 79-89.

92. I. Ismail, S. A. Bernal, J. L. Provis, R. San Nicolas, S. Hamdan and J. S. van Deventer, Cem. Concr. Compos., 2014, 45, 125-135.

93. C. Shi, Z. Shi, X. Hu, R. Zhao and L. Chong, Mater. Struct., 2015, 48, 621628.

94. P. Krivenko, R. Drochytka, A. Gelevera and E. Kavalerova, Cem. Concr. Compos., 2014, 45, 157-165.

95. R. Tänzer, Y. Jin and D. Stephan, Cem. Concr. Res., 2017, 98, 82-90.

96. Y. Chen, X. Pu, C. Yang and Q. Ding, Journal of Wuhan University of Technology-Mater. Sci. Ed., 2002, 17, 60-62.

97. K. Kupwade-Patil and E. N. Allouche, J. Mater. Civ. Eng., 2012, 25, 131139.

98. T. Williamson and M. C. Juenger, Cem. Concr. Res., 2016, 83, 124-130.

99. C. Tennakoon, A. Shayan and J. Sanjayan, Concrete Institute of Australia Conference, 27th, 2015, Melbourne, Victoria, Australia, 2015.

100. B. Singh, G. Ishwarya, M. Gupta and S. Bhattacharyya, Advances in chemically activated materials, Changsha, China, 2014.

101. M. Cyr and R. Pouhet, in Handbook of Alkali-Activated Cements, Mortars and Concretes, Elsevier, 2015, pp. 397-422.

102. R. Tänzer, Y. Jin and D. Stephan, Mater. Struct., 2017, 50, 91.

103.Z. Shi, C. Shi, S. Wan and Z. Ou, Constr. Build. Mater, 2017, 143, 16-23.

104. Q. Wang, Z. Ding, L. Li, C. Zhang and Z. Sui, in First international conference on advances in chemically-activated materials, Jinana, Shandong, Jinana, Shangdong, 2010, pp. 131-138.

105. H. Wang, C. Lu, W. Jin and Y. Bai, J. Mater. Civ. Eng., 2011, 23, $1043-$ 1049

106. N. B. V. Rakesh, D. M. N. Hegde and T. Chandrasekaraiah, International Journal of Advancement in Engineering Technology, Management \& Applied Science, 2014, 1, 91-101.

107. R. Bayuaji, M. S. Darmawan, B. Wibowo, N. Husin and S. Subekti, The Open Civil Engineering Journal, 2016, 10, 782-793.

108. D. V. Reddy, J.-B. Edouard and K. Sobhan, J. Mater. Civ. Eng., 2012, 25, 781-787.

109. W. Yodsudjai, Advances in Science and Technology, 2014, 92, 74-83.

110. K. Kannapiran, T. Sujatha and S. Nagan, Asian Journal of Civil Engineering, 2013, 14, 225-235.

111. G. Mathew and B. Joseph, Journal of Building Engineering, 2018, 15, 311317.

112. K. Pasupathy, M. Berndt, A. Castel, J. Sanjayan and R. Pathmanathan, Constr. Build. Mater., 2016, 125, 661-669.

113. T. Li, Y. Zhang and J.-G. Dai, Constr. Build. Mater, 2017, 152, 651-660.

114. P. K. Sarker and S. Mcbeath, Constr. Build. Mater., 2015, 90, 91-98.

115. K. Pasupathy, M. Berndt, J. Sanjayan, P. Rajeev and D. S. Cheema, Cem Concr. Res., 2017, 100, 297-310.

116. Z. Zhang, Y. Yao and H. Wang, Appl. Clay Sci., 2012, 67, 57-60.

117. B. Varela and N. Privorotskaya, in Proceedings of the Geopolymer 2005 World Congress, ed. J. Davidovits, 2005, pp. 209-211.

118. K. Sakkas, P. Nomikos, A. Sofianos and D. Panias, in World Tunel Congress 2013, Taylor \& Francis Group, Geneva, Switzerland, 2013, pp. 343-349.

119. J. Temuujin, A. Minjigmaa, W. Rickard, M. Lee, I. Williams and A. Van Riessen, J. Hazard. Mater, 2010, 180, 748-752.

120. J. Temuujin, A. Minjigmaa, W. Rickard, M. Lee, I. Williams and A. Van Riessen, Appl. Clay Sci., 2009, 46, 265-270.

121.F. Škvára, L. Kopecký, J. Nemecek and Z. Bittnar, Ceramics-Silikaty, 2006 , 50, 208-215.

122. S. Thokchom, P. Ghosh and S. Ghosh, Can. J. Civ. Eng., 2011, 39, 34-43.

123.D. W. Law, A. A. Adam, T. K. Molyneaux, I. Patnaikuni and A. Wardhono, Mater. Struct., 2015, 48, 721-731.

124. Y. Ma, J. Hu and G. Ye, Fuel, 2013, 104, 771-780

125. C. Shi and Y. Li, Cem. Concr. Res., 1989, 19, 527-533.

126. A. Noushini and A. Castel, Constr. Build. Mater., 2016, 112, 464-477.

127. Sindhunata, J. S. J. Van Deventer, G. C. Lukey and H. Xu, Industrial \& Engineering Chemistry Research, 2006, 45, 3559-3568.

128. D. Ravikumar, S. Peethamparan and N. Neithalath, Cem. Concr. Compos., 2010, 32, 399-410.

129. B. S. Gebregziabiher, R. J. Thomas and S. Peethamparan, Constr. Build Mater, 2016, 113, 783-793.

130. P. Rovnaník, Constr. Build. Mater., 2010, 24, 1176-1183.

131. V. Sreevidya, R. Anuradha, D. Dinakar and R. Venkatasubramani, Int. J. Eng. Sci., 2012, 4, 681-684.

Publisher's Note Engineered Science Publisher remains neutral with regard to jurisdictional claims in published maps and institutional affiliations. 